\title{
El contrato de seguro y los contratos de la actividad financiera: Coberturas y tendencias del seguro global bancario*
}

\author{
Jorge Eduardo Narváez Bonnet**
}

\begin{abstract}
Para Citar este artículo/To cite this article
Narváez Bonnet, Jorge Eduardo, El contrato de seguro y los contratos de la actividad financiera: Coberturas y tendencias del seguro global bancario, 43 RIS, 49-102 (2015). http://dx.doi. org/10.11144/Javeriana.ris43.csaf

doi:10.11144/Javeriana.ris43.csaf

SUMARIO

I. CONSIDERACIONES PREVIAS

II. LA POLIZA GLOBAL BANCARIA

1. Desarrollo reciente de este tipo de productos en el mercado internacional

* Artículo desarrollado en el marco de la conferencia dictada por el autor en el Congreso de ACOLDESE año 2015.

** Abogado de la Pontificia Universidad Javeriana. Profesor de la Especialización en Seguros de la Universidad Externado de Colombia, de la Especialización en Seguros y de la Maestría en Seguros de la Universidad Javeriana. Realizó cursos en materia de seguros en el College of Insurance del Chartered Insurance Institute de Londres; College de Business Administration de Georgia State University, Atlanta, EEUU; Seguros, Reaseguros y Gestión de Empresa -Swiss Insurance Training Center de la Compañía Suiza de Reaseguros; entrenamiento en seguros bancarios en la firma BRS de Londres; especialización en Seguros en la Pontificia Universidad Javeriana. Socio de la firma Narváez \& Peláez -Abogados-; abogado litigante y consultor; árbitro de los Centros de Arbitraje de la Cámara de Comercio de Bogotá, de la Federación Nacional de Comerciantes -FENALCO- y de la Sociedad Colombiana de Ingenieros -SCl-. Investigador del Departamento de Derecho Privado de la Pontificia Universidad Javeriana. Es autor de varios libros, entre ellos, "El contrato de seguro en el sector financiero", así como autor de diversos artículos en aspectos especializados en materia de seguros y reaseguros. Contacto: narvaezypelaez@hotmail.com
\end{abstract}


1.1 El amparo de infidelidad de empleados

1.2 Amparo de infidelidad de empleados y dolo eventual

1.3 Otros amparos de la póliza

2. El descubrimiento de pérdidas: precisiones sobre los presupuestos para su configuración

3. La supuesta abusividad de algunas estipulaciones de la póliza global bancaria

\subsection{Consideraciones generales}

3.2 La abusividad que se endilga a las condiciones del amparo de infidelidad

3.3 La supuesta abusividad de la cláusula de limitación de descubrimiento

3.4 Amparo de infidelidad y pérdidas operacionales

III. LAS COBERTURAS COMPLEMENTARIAS AL AMPARO DE LA GLOBAL BANCARIA

1. El cometido de tales coberturas

2. La cobertura de responsabilidad civil profesional

2.1 El propósito de esta cobertura

2.2 El clausulado más reciente de responsabilidad profesional bancaria

3. El amparo de fraudes por sistemas computarizados

3.1 El objeto de la cobertura

3.2 Las tendencias de cobertura en el mercado internacional

4. Las coberturas de cyber risks y de cyber liability

\section{RESUMEN}

Este artículo corresponde a la ponencia presentada por el autor el XXVIII Congreso de la Asociación Colombiana de Seguros -ACOLDESE- celebrado en la ciudad de Medellín en octubre de 2015.

Se analizan los principales desarrollos en materia de pólizas globales bancarias en las ú7ltimas décadas, si bien las pólizas que se utilizan en el mercado colombiano, provienen del Reino Unido, las cuales no han sufrido cambio alguno, la forma americana No. 24 que sirvió de base a las pólizas inglesas, evidentemente ha sufrido distintos ajustes y alteraciones, particularmente, en el amparo de infidelidad de empleados. 
El análisis también comprende diversos tópicos, como son: la configuración del descubrimiento según los parámetros de la jurisprudencia americana; la supuesta abusividad de las cláusulas de infidelidad de empleados y de limitación de descubrimiento en estas pólizas; la extensión del deber de mitigar el daño.

Finalmente, el autor realiza un breve recuento de los desarrollos más recientes de las coberturas de responsabilidad profesional bancaria, de fraudes por sistemas computarizados y de los amparos denominados "cyber risks" y "cyber liability".

Palabras clave: infidelidad de empleados, pólizas globales bancarias, descubrimiento de pérdidas, cláusulas abusivas.

Palabras claves descriptor: estandarización, intención manifiesta, activo y consciente propósito de causar la pérdida al asegurado, dolo eventual, descubrimiento de pérdidas, cláusula de infidelidad, cláusula de limitación de descubrimiento, responsabilidad en operaciones bancarias.

\section{ABSTRACT}

This article corresponds to the presentation made by the author at the XXVIII Congress of the Colombian Association of Insurance Law -ACOLDESE- held in the city of Medellin in October 2015.

Major developments in global banking policies in the last decades are analyzed; while policies used in the Colombian market, come from the UK, which have remained unchanged, the American form No. 24 which served as basis of the different english wordings, has been modified through various adjustments and alterations, particularly in relation with infidelity of employees clause.

The analysis also includes various topics, such as: the configuration of discovery according to the parameters adopted by the american courts; the alleged abusiveness of infidelity clauses and limitation of discovery clauses and the extent for the duty to mitigate damages.

Finally, the author makes a brief account of the most recent developments in on banking professional indemnity coverages, computer systems fraud coverages and the products called "cyber risks" and "cyber liability".

Key words: infidelity of employees, banker's blanket bonds, discovery of losses, unfair terms.

Key words descriptor: standardization, manifest intent, active and conscious intent to cause loss to the insured, gross negligence and dol, discovery of losses, infidelity of employees clause, discovery limitation clause, liability arising from banking operations. 


\section{CONSIDERACIONES PREVIAS}

Este evento académico pone de relieve las relaciones del contrato de seguro con la teoría general del contrato y algunos contratos especiales, por lo que brevemente pretendo sentar algunas premisas que permitan desarrollar el tema de "Coberturas y tendencias del seguro global bancario".

El doctrinante español Ricardo De Angel Yagüez respecto de la unidad del ordenamiento jurídico expresa: "El Derecho positivo de un país, es decir, el conjunto de las normas jurídicas vigentes, constituye una unidad" y añade: "esta integridad no impide distinguir dentro del Derecho ciertas divisiones o ramas. En efecto, son muy conocidas en la ciencia jurídica algunas clasificaciones del Derecho, basadas sobre todo en los diferentes ámbitos o sectores de la vida social que él regula. Éstas clasificaciones responden en principio a determinados criterios científicos, con vistas a un análisis sistemático y coherente de la reglas e instituciones jurídicas; pero se manifiestan también en el terreno didáctico (a efectos de la enseñanza del Derecho) y en el campo profesional (como fundamento para todo intento de especialización)"1.

De manera que si bien esas clasificaciones se estructuran para su análisis sistemático, es innegable que la iniciativa de los particulares en la producción y comercialización de bienes y servicios la materializan a través de vínculos obligacionales de contenido patrimonial y que no se limitan al campo del Derecho civil, por lo que su quehacer cotidiano en la actividad económica desborda los cauces propios del Derecho común y, aún del Derecho privado.

1 De Ángel, Ricardo. "Una teoría del Derecho". Colección tratados y manuales, Editorial Civitas S.A. Madrid, 1995, página 123. 
De ahí porque, algunos prefieran aducir la subsidariedad del régimen de obligaciones del Derecho Común en las diversas ramas del Derecho, mientras que otros, con una variación de enfoque, optan por calificarla como prevalencia del régimen general de las obligaciones.

A este respecto, el doctrinante antes citado asevera que: “... el Derecho Civil reviste la importancia de ser el fundamento dogmático de todo el Derecho privado. Sus conceptos e instituciones han sido tomados por otras disciplinas y puede decirse que constituyen la columna vertebral de la ciencia jurídica"2.

Ciertamente, ese criterio lo acoge nuestro Derecho positivo, sin desconocer el sentido propio o las particularidades que llega a alcanzar en cada una de las ramas del Derecho, por ello el régimen propio de las obligaciones en el Derecho Común es aplicable de manera genérica a las relaciones jurídicas intersubjetivas en los distintos ámbitos de la contratación.

Por su parte, el Derecho mercantil como manifestación de la ciencia jurídica que se ocupa del empresario, la empresa y las actividades de ésta3, se nutre subsidiariamente del Derecho común y es así como el artículo 822 del código de comercio dispone que: "Los principios que gobiernan la formación de los actos y contratos y las obligaciones de derecho civil, sus efectos, interpretación, modo de extinguirse anularse

2 Ob. Cit., página 142.

3 Sobre el particular, José Ignacio Narváez García expone: "En Colombia el ordenamiento mercantil regula incontables relaciones surgidas directa o únicamente de la producción, la transformación, la circulación, la administración o la custodia de bienes, y de la prestación de servicios en el mercado. Y sus normas se aplican a quienes se involucran de manera permanente $u$ ocasional en operaciones, negocios o actividades mercantiles. $Y$ por ésta se entiende no sólo el intercambio o mediación (noción tradicional de comercio) sino también aquellas en las cuales se crean, desarrollan y extinguen relaciones jurídicas patrimoniales que vinculan a dos o más personas, o a éstas con un bien corporal o inmaterial.

"Tales relaciones pueden ostentar carácter principal, accesorio conexo o simplemente accidental y los sujetos de las relaciones son, además de los empresarios, cualquier persona que sin tener ese status, realice negocios, actos u operaciones mercantiles" y agrega: "Tal materia tiene su peculiar dinamismo al impulso de las transformaciones económicas, sociales y culturales, y en la medida en que la ley dota de valor jurídico nuevos hechos, situaciones y relaciones que impone el respectivo grado de desarrollo, sobreviene la mutabilidad de sus linderos. A ese resultado contribuyen el extraordinario desenvolvimiento del comercio internacional; la celeridad y el ritmo constante de las transacciones; el creciente número de personas y entidades que en cada país se dedican a las actividades económicas, principales y auxiliares o complementarias; la realización cotidiana de operaciones y contratos mercantiles por quienes no tienen intención de convertirse mercaderes, la potencialidad mobiliaria; la proliferación de compañías; la estructuración de grandes empresas y consorcios industriales; la comercialización de innumerables servicios; la diversidad de medios de comunicación; la multiplicidad de documentos utilizados en los negocios, con o sin el carácter de títulos- valores" (En "Introducción al derecho mercantil", Legis Editores, Bogotá, 2002, página 70). 
o rescindirse, serán aplicables a las obligaciones y negocios mercantiles, a menos que la ley establezca otra cosa" ${ }^{4}$.

Ahora bien, en ese ámbito mercantil, la enumeración que hace el artículo 20 del Código de Comercio de las actividades que la ley reputa como mercantiles, el numeral 10 consagra: "Las empresas de seguros y la actividad aseguradora", con la aclaración que: "Se tendrán así mismo como mercantiles todos los actos de los comerciantes relacionados con actividades o empresas de comercio, y los ejecutados por cualquier persona para asegurar el cumplimiento de obligaciones comerciales" (art.21, ibídem), con lo cual no queda resquicio de duda sobre el carácter mercantil que le es propio y lo cual conlleva la aplicación preeminente de sus disposiciones.

Y como una característica descollante del Derecho Comercial es la especialidad de sus normas, esto explica que el artículo 1ㅇ․ Del estatuto mercantil colombiano disponga: "Los comerciantes y los asuntos de mercantiles se regirán por las disposiciones de la ley comercial, y los casos no regulados expresamente en ella serán decididos por analogía de sus normas" (se destaca) y el artículo $2^{\circ}$ del mismo estatuto aclara que: "En las cuestiones comerciales que no pudieren regularse conforme a la regla anterior, se aplicarán las disposiciones de la legislación civil" (se destaca).

En cuanto al orden para la aplicación de los preceptos de la legislación civil, el Proyecto de Código de Comercio de 1958 expresa que: "Las disposiciones civiles son, pues, las últimas que se aplican a los asuntos de comercio, no como reglas de derecho comercial propiamente, sino como reglas de derecho común. Se reduce considerablemente su campo de aplicación, puesto que primero han de aplicarse los varios grupos de reglas que quedan enunciadas. Las únicas disposiciones del código civil que se aplican en el mismo orden que corresponde a las disposiciones de la ley comercial son las que ésta invoca expresamente (art. 8o.), con lo cual no es que dejan de ser normas de derecho civil para convertirse en normas de derecho comercial, sino que como reglas de derecho común, adquieren una prelación u orden de aplicación que no tendrían sin esa invocación expresa de la ley mercantil, porque satisfacen las conveniencias de la vida de los negocios o porque corresponden a cuestiones en las que no es necesario romper la unidad orgánica del derecho privado"s.

4 Este precepto deviene del artículo 221 del Proyecto de Código de Comercio de 1958 que es del siguiente tenor: "Los principios que gobiernan la formación de los actos y contratos y las obligaciones de derecho civil, sus efectos, interpretación, modo de extinguirse y anularse o rescindirse y su prueba, serán aplicables a las obligaciones y negocios jurídicos mercantiles, salvas las modificaciones establecidas en este Código y en las leyes especiales del comercio". ("Proyecto de Código de Comercio", Ministerio de Justicia, Tomo I, julio de 1958, página 48).

5 Proyecto de Código de Comercio", Ministerio de Justicia, Tomo I, julio de 1958, páginas 13 y 14 
De manera que, en materia mercantil, la aplicación de las normas corresponde a la siguiente jerarquía: las disposiciones mercantiles (art. 10); las estipulaciones contractuales en cuanto no pugnen con normas imperativas (art. 40); la costumbre mercantil cuando no contraríe manifiesta o tácitamente la ley mercantil, siempre que los hechos constitutivos de la misma sean públicos, uniformes y reiterados en el lugar donde hayan de cumplirse las prestaciones, es decir, cuando satisface la función normativa (art. 3o); los tratados o convenciones internacionales de comercio no ratificados por Colombia, la costumbre mercantil internacional y los principios generales de derecho comercial ( art. 7o) y, finalmente, la disposiciones de la legislación civil (art. 2o).

En lo relativo al marco propio de la actividad aseguradora, ésta es materia de disposiciones que la regulan a los sujetos que pueden realizarla y el ámbito de sus operaciones, como también el ámbito del contrato de seguro, lo que ha venido a conformar el denominado Derecho de Seguros6; como arista descollante de la actividad,

6 El connotado tratadista español Luis Benítez de Lugo al señalar que en el campo del derecho se estructuran disciplinas jurídicas propias e independientes que ofrecen características y singularidades que demandan ser agrupadas aparte, señalaba que: "... en el derecho privado ofrecen características propias el Derecho Civil, Derecho Mercantil, Derecho Hipotecario, etc., Y en análogas circunstancias, y en base de reunir una singular sustantividad propia de obligada sistematización se encuentra el Derecho de seguros. Para ello bastaría recordar algunas de las reglas jurídicas distintas de las que presiden el derecho de sucesiones en cuanto al beneficiario; nulidad, rescisión, resolución, denuncia y "resiliación" contractuales; consecuencias derivadas de la modificación del riesgo, medios de prueba, transmisión de la cosa asegurada, subrogación, representación (seguro por cuenta de otro o de quien corresponda), efectos del impago de la prima, alcance del peritaje de siniestro, regla de la preexistencia, regla proporcional, concurso quiebra del asegurado, etc." ("Tratado de Seguros", Tomo I, Instituto Editorial Reus, Madrid, 1955, página 20). Sobre este mismo aspecto, Narváez García anota: "... la pragmática realidad muestra que la complejidad y extensión de algunas actividades económicas con características muy peculiares han determinado una paulatina estructuración de especialidades cuasiautónomas, que facilitan el análisis en profundidad de todas las aristas y dimensiones de negocios jurídicos o grupo de contratos afines dentro del contexto propio de aquellas. Esa tendencia explica la abundancia de obras sobre Derecho del Transporte, Derecho de Seguros, Derecho Societario, Derecho Bursátil, Derecho Bancario, Derecho Marítimo, Derecho Cambiario, Derecho Aéreo, Derecho Concursal etc., Que tradicionalmente se ha considerado sectores de la materia mercantil" y citando al doctrinante argentino Rodolfo Fontanarrosa añade: "En los años más recientes - y como consecuencia del rápido desarrollo de la tecnología, de la magnitud y capacidad financiera de las empresas, de la contratación en masa, de la mayor intervención del Estado en las actividades privadasse advierte una pronunciada tendencia regular mediante leyes especiales muchos aspectos de la vida comercial. Así se da esta aparente paradoja: que en tanto se pretende -por una parte- suprimir la distinción entre comerciantes y no comerciantes mediante la unificación del régimen aplicable (v.gr., Unificación de los concursos civiles y quiebras), por otra parte se dictan leyes reguladoras de ciertas situaciones y actividades específicamente mercantiles. Este fenómeno induce a considerar que la materia comercial tienda cada vez más a escapar a la regulación única del Código de Comercio y a provocar la fragmentación legislativa (pero no la dogmática o científica) del derecho comercial".("Introducción al derecho mercantil", Ediciones Doctrina y Ley, Bogotá, 1995, página 65). 
se encuentra la libertad de gestión para definir los productos o tarifas y, claro está, para la delimitación del riesgo que es materia de amparo en la respectiva cláusula operativa y, por supuesto, cuando se trata de cubrir contingencias derivadas de ciertas actividades que los empresarios despliegan en el tráfico negocial, a ese estado del riesgo lo nutre la reglamentación legal de las mismas, como también los pronunciamientos jurisprudenciales que relievan sus características y alcance, por lo que ese cuerpo normativo y jurisprudencial contribuye a alinderar el perfil objetivo del riesgo de la actividad que es materia de aseguramiento, determina el grado de exposición que proyecta ese riesgo objetivo, por cuanto de allí se derivan contingencias que pueden ser o no materia de cubrimiento o de protección por parte del asegurador, o si se quiere, permiten apreciar con mayor nitidez, las aristas del riesgo asegurado que es materia de un contrato de seguro en particular.

En este sentido y, a manera de ejemplo, los seguros previsionales se nutren de aspectos específicos del régimen jurídico en materia pensional; los seguros de cumplimiento guardan una conexidad material con el régimen de contratación público o privada, según sea la naturaleza de la relación contractual que pretendan garantizar a través de su diversos amparos y claro está, en los seguros orientados a cubrir riesgos de la actividad bancaria o financiera, los desarrollos que en la praxis presente, como en el marco legal y regulatorio, van a cobrar trascendencia para identificar las tendencias de aseguramiento o de restricción en las coberturas existentes, es decir, evidencian riesgos que van incursionando y que en algunos casos son materia de aseguramiento y, en otras hipótesis, pueden no ser medibles o cuantificables, de acuerdo con la ciencia actuarial, o que sus verdaderos implicaciones se ignoren, por lo que resultan inasegurables al no despertar el apetito de los aseguradores de asumirlos.

De manera que lo que caracteriza la actividad bancaria y financiera como se desarrolla hoy día, es un amplio soporte tecnológico que ha implicado no pocas modificaciones en la forma de operación tanto de los bancos como de las entidades financieras y, por consiguiente, esa realidad se proyecta en los contratos en que tales operaciones resultan plasmadas.

En efecto, el denominado dinero plástico es el mecanismo principal de disposición de fondos al igual que las transferencias electrónicas, aparejadas de la operación de las cámaras de compensación automatizadas, lo cual conlleva una mayor exposición en relación con los delitos informáticos y a una preocupación creciente por la protección en el manejo de las bases de datos.

De otro lado, las directrices de los acuerdos de Basilea se han proyectado en los parámetros de supervisión y regulación y como consecuencia de ello, hoy día, se hace particular énfasis en la gestión y administración de los riesgos que están presentes en este tipo de actividades y lo cual se refleja en los modelos de gestión de riesgos y en las exigencias de carácter patrimonial que los actores de la actividad deben cumplir como consecuencia de esa valoración de riesgos. 
A este nuevo espectro de riesgos, se suma la mayor protección al consumidor financiero y el auge que han venido cobrando las acciones colectivas y de grupo.

En consecuencia, como la actividad bancaria y financiera es eminentemente dinámica, marcha en ocasiones muy por delante de los marcos legales y regulatorios, ante la innovación permanente, la tecnificación de sus operaciones, la robustez y extensión de su infraestructura operacional, la ampliación de sus bases de clientes; estas circunstancias conllevan que el universo de riesgos a que se encuentran expuestos, con el correr de los días presente nuevas realidades, como también exigencias cada vez mayores, respecto de los estándares para el desempeño de sus operaciones en los diversos ámbitos y, particularmente, en lo que interesa para propósitos de este escrutinio, en lo regulatorio y a nivel jurisprudencial.

Para cumplir con el cometido del encargo que me fuera asignado, la ponencia se ha dividido en dos grandes secciones: la primera de ellas destinada a examinar diversos desarrollos que ha experimentado la versión base de las pólizas globales bancarias, como lo es la forma americana No. 24, con una referencia somera a debates que se han presentado en frente de diversas reclamaciones en los últimos tiempos y, en una segunda parte, se enuncian muy brevemente los desarrollos más sobresalientes de las coberturas estrechamente vinculadas a ésta, con excepción de la póliza de directores y administradores, por cuanto es tema materia de otra ponencia.

\section{LA PÓLIZA GLOBAL BANCARIA}

\section{Desarrollo reciente de este tipo de productos en el mercado internacional}

A diferencia de lo que acontece en frente de las grandes corporaciones bancarias internacionales, en nuestro medio, suelen introducirse clausulados enteros impuestos por el reasegurador que obedecen a formatos estándar, ante la exigencia para el asegurador que la póliza expedida al asegurado se adecue de la manera más fiel y cercana posible al reaseguro contratado.

Ante esa estandarización, los clausulados son ampliados o modificados excepcionalmente, pues los reaseguradores son reacios a extender, modificar o alterar la cobertura y, cuando a ello acceden, por lo general, acuden a extensiones de cobertura prediseñadas o suficientemente decantadas. ${ }^{7}$

$7 \quad$ En el caso colombiano, es corriente encontrar las siguientes ampliaciones: la extensión para obras de arte bajo la definición de bienes asegurados; la ampliación de la definición de empleados respecto de funcionarios de empresas contratistas de servicios de seguridad y mantenimiento y de personas de compañías de servicios temporales; extensión de motín, conmoción civil y actos malintencionados de terceros; cobertura para servicios especiales de recaudo y pago de cuentas de servicios públicos y privados en predios de clientes; cobertura para el servicio de entrega y distribución de nóminas bajo los amparos 
De manera que estos productos no resultan estructurados acorde con las exigencias de cada entidad bancaria o financiera, no son delineados a la medida de cada cliente.

Como las pólizas globales bancarias y las coberturas conexas fueron diseñadas para bancos comerciales, otorgan protección respecto de los riesgos propios de la prestación de los servicios bancarios y claro está, no tienen la virtud de cubrir todos los riesgos que puedan estar presentes en el ámbito de las actividades de un banco comercial, porque este tipo de póliza no es más que un componente dentro de todo el programa de seguros, que, ciertamente, contemplará otros amparos y, por ende, diversas tipos de coberturas de seguros.

Ahora bien, es ampliamente conocido que el origen de este tipo de pólizas se encuentra en la forma americana No. 24 que fue desarrollada por la American Banker`s Association y la Surety Asociation of America, por lo cual es un referente ineludible cuando se cumple el examen de este tipo de productos8; versión americana que ha sido materia de alteraciones, supresiones y adiciones de particular trascendencia, principalmente en el amparo de infidelidad de empleados; modificaciones que obedecen o se justifican, en pronunciamientos de los tribunales americanos que han conducido a los aseguradores a precisar el significado de los riesgos que se pretende amparar a través de ellas, como también, responden a la implantación casi generalizada de la tecnología en las actividades bancarias, con el correlativo aumento de la potencialidad de pérdidas, los cambios en los patrones de defraudación y que, suelen presentar como rasgos característicos: la alteración de registros encaminados a la apropiación de fondos; la simulación de operaciones, compras y préstamos.

Paradójicamente, si bien esa forma americana No. 24 influenció las versiones inglesas (que son precisamente las utilizadas en el mercado local), éstas últimas no han tenido modificación en las últimas décadas.

Y como en la hora actual, en la actividad bancaria y financiera se identifican como áreas de mayor exposición, las plataformas tecnológicas y la infidelidad de empleados, las modificaciones de la forma americana No. 24 han obedecido a esas mutaciones en la naturaleza de las operaciones bancarias y a las interpretaciones de algunos tribunales americanos que, en criterio de los aseguradores, desbordaron la finalidad y el propósito de la cobertura inicialmente prevista.

de predios y tránsito; extensión bajo el amparo de predios para cajeros automáticos; inclusión de pérdidas resultantes de tarjetas de crédito y/o débito respecto al amparo de infidelidad de empleados únicamente, entre otros.

8 La primera versión de la forma No. 24 data del 8 de junio de 1916 y ha tenido modificaciones posteriores en 1941, 1946, 1951, 1969, 1986 y 2004. A partir de 1986, su denominación cambió a "Financial Institution Bond Standard Form No 24" para dar cabida a otras instituciones financieras y su forma de operación, tuvo una modificación significativa, como quiera que el límite asegurado que operaba por pérdida se convirtió en límite agregado de responsabilidad durante la vigencia. 
La revisión más reciente se cumplió en el año 2004; ocasión en que, entre otras cosas, se restringió la cobertura a transacciones derivadas de documentos físicos (paper transactions), de tal forma que las entidades que requirieran amparo para riesgos electrónicos, instrucciones fraudulentas de transferencias electrónicas y fraude a través de sistemas computarizados, adquirieran la protección a través de los correspondientes anexos.

\subsection{El amparo de infidelidad de empleados}

En el amparo de infidelidad de empleados se identifican tres elementos básicos: en primer lugar, la pérdida directa; en segundo término, los actos deshonestos o fraudulentos y finalmente, que tales actos sean cometidos por empleados del asegurado. ${ }^{9}$

Respecto del primer elemento, los tribunales americanos han sostenido que como el término pérdida no se encuentra definido en el clausulado de esta clase de pólizas, significa una pérdida actual, una reducción o privación de fondos para el asegurado ocasionada por el acto de deshonestidad del empleado y, en este sentido, la pérdida directa puede incluir también la pérdida por depreciación de garantías que estén relacionadas con un préstamo fraudulentamente efectuado; igualmente, en esa expresión de pérdida directa quedan comprendidos los detrimentos que los funcionarios ocasionen a terceros, que comprometan la responsabilidad de la entidad asegurada, por razón de sus actos deshonestos o fraudulentos que resulten en la apropiación o hurto de valores o fondos de terceros, que se encuentren bajo la tenencia o custodia física de empleados del asegurado ${ }^{10}$.

Íntimamente relacionado con este aspecto, en lo relativo a la exclusión de pérdidas operacionales (trading loss exclusion), -que tiene por finalidad colocar por fuera de la

$9 \quad$ El amparo de infidelidad de empleados, comprende las conductas intencionales y los actos voluntarios, ya sea que consistan en acción u omisión de los empleados, clara y directamente encaminados a causarle un perjuicio al banco. No se ampara únicamente la pérdida de dinero y valores, sino que se trata de cualquier bien que, de acuerdo con la definición contenida en la póliza, tenga el carácter de "bien asegurado". Como la finalidad de este amparo se circunscribe a actos dolosos de empleados del asegurado, quedan excluidos los comportamientos dañosos en que incurran los empleados del asegurado por impericia, error o negligencia. Estos vienen a ser objeto específico de coberturas como las de errores y omisiones y responsabilidad profesional, aunque con diversas restricciones. Igualmente, la cobertura no abarca pérdidas operacionales del asegurado. En consecuencia, las negociaciones con valores o divisas o las diversas modalidades de concesión de créditos solo gozan de la cobertura si provienen de actos deshonestos de empleados del asegurado, ejecutados con la finalidad manifiesta de lucrarse y siempre que el beneficio pecuniario no consista en salarios, comisiones, honorarios, promociones o cualquier tipo de emolumento de naturaleza similar.

10 Horkovich, Robert M. "Insurance coverage for employee theft losses: a policyholder primer a commonly litigated issues", University of Memphis Law Review, September 2008, página 4. 
cobertura las pérdidas resultantes de negociaciones de valores y, por lo mismo, pretende remover el riesgo proveniente de pérdidas y transacciones ordinarias de negocios o de pérdidas ocasionadas por las oscilaciones o variaciones de los mercados-, los tribunales americanos la han interpretado de manera restrictiva, es decir, esta exclusión se refiere solamente a los resultados deficitarios derivados de condiciones de mercado o al comportamiento de variables macroeconómicas, pero no se extiende a pérdidas derivadas de deshonestidad o fraude ${ }^{11}$.

Ahora bien, ante un aspecto que surge en la generalidad de reclamos por pérdidas por infidelidad de empleados como es la eventual falla o manipulación de los controles internos del asegurado que facilitan o contribuyen a mantener oculta la pérdida, los tribunales han estimado que esa falta de efectividad de los controles del asegurado, no es admisible para rechazar un reclamo, por cuanto el asegurador considero esos mismos controles aceptables al momento de emitir la póliza y de establecer la prima al asegurado.

Postura ésta última que, sin duda, obedece a que en la práctica lo que acontece es que los controles son vulnerados por los empleados deshonestos para la comisión de los actos defraudatorios, por lo que su violación o quebrantamiento, no significa que tales controles no se encontraran en operación, habida cuenta que lo usual es que esas maniobras sean ampliamente planeadas y ejecutadas de manera meticulosa para mantenerlas ocultas, y en no pocas ocasiones, con un grado de sofisticación que genera perplejidad.

En cuanto al segundo elemento, vale decir, la extensión del amparo de infidelidad de empleados, desde la modificación introducida en 1980 en la forma No. 24, era preciso que se tratara de actos deshonestos o fraudulentos cometidos por empleados del asegurado con la "intención manifiesta" de ocasionar al asegurado una pérdida y de obtener un beneficio financiero ${ }^{12}$; exigencias de "intención manifiesta" y de "bene-

11 HORKOVICH, Robert M. op. cit., página 5.

12 Los clausulados más utilizados en el mercado local contemplan distinto tipos de exigencias como se evidencia de su sola lectura.

KFA- 81- "Infidelidad de empleados: Pérdida que resulte única y directamente de actos deshonestos o fraudulentos por parte de empleados del asegurado cometidos con la intención manifiesta de hacer que el asegurado sufra dicha pérdida o para obtener una ganancia económica para ellos mismos, cometidos en cualquier momento y donde quiera que sean cometidos y ya sea que los cometiera solo o en concurso con otros, incluyendo pérdida de bienes a través de cualquiera de tales actos por parte de empleados.

"No obstante lo anterior, se acuerda que con respecto a intercambios comerciales $u$ otros en valores, mercancías, moneda, divisas extranjeras y similares, préstamos u otras prolongaciones de créditos, esta póliza cubre única y directamente los actos deshonestos o fraudulentos por parte de empleados del asegurado cometidos con la intención manifiesta de hacerlo y el cual resulte en un provecho indebido para ellos mismos distinto de salarios, honorarios, comisiones, promociones y otros emolumentos similares".

DHP- 84 "Deshonestidad de los empleados: cualquier pérdida que provenga directamente de actos deshonestos o fraudulentos de empleados del asegurado, cometidos, solos o en 
ficio pecuniario" que fue preciso introducirlas, por cuanto la versión inmediatamente anterior amparaba las pérdidas resultantes de esos actos deshonestos y fraudulentos, sin exigencia adicional alguna $y$, ante ese panorama, en algunos pronunciamientos de tribunales americanos, se consideró que el acto deshonesto podía comprender la mera negligencia, porque bajo una interpretación amplia de éste, el acto deshonesto era un proceder moral y legalmente reprochable.

De manera que esos presupuestos de "intención manifiesta" y de "beneficio financiero", persiguieron dejar claramente establecido que el amparo no se refería a conductas negligentes y lo cual se pretendió enfatizar a través de la inclusión de las exclusiones de: ingresos potenciales; daños de cualquier tipo respecto de los cuales se impute responsabilidad al asegurado; costos, honorarios y otros gastos incurridos por el asegurado para establecer el monto de la pérdida; pago o retiro de la cuenta de un depositante que hubieren sido acreditados de manera errónea; exclusiones todas ellas, que presentan como común denominador, excluir pérdidas por responsabilidad del banco ante negligencia de sus funcionarios, al igual que las pérdidas de carácter consecuencial y los beneficios dejados de percibir por la entidad bancaria ${ }^{13}$.

Ciertamente, la interpretación de las Cortes, despertó amplia controversia; como se centró en la palabra "intención", en criterio de algunos, dejó de lado que la expresión no era "intención" solamente sino "intención manifiesta", lo cual conlleva un calificativo de notoriedad, mientras que otros estimaron que si bien debía tratarse de "intención manifiesta", lo cierto era que en algunos casos, ese tipo de intención resultaba evidente $y$, de manera particular, en esas circunstancias donde un resultado en concreto es sustancialmente cierto que se llegue a producir, como consecuencia de la conducta desplegada por el empleado.

Otros más, adujeron que la exigencia de "intención manifiesta", era superflua, habida cuenta que podía inferirse de las circunstancias que originan la pérdida del asegurado y, por tanto, dicha intención resultaba acreditada a través de la evidencia sobre la pérdida misma, como resultado natural de un acto voluntario ejecutado por un empleado del asegurado y, aún en la hipótesis que el empleado no deseara ocasionar dichas pérdidas, resultaba manifiesto que conocía que con su proceder, de manera necesaria o probable, ocasionaría tales consecuencias, por lo que se colegía su intención de causarlas y, en este orden de ideas, si la conducta del empleado era descuidada, la consecuencia obvia era una pérdida para su empleador.

En otras palabras, bajo esos parámetros, existe intención, cuando el empleado de manera consciente y deliberada desea el resultado, sin importar la probabilidad de que el resultado querido se materialice como consecuencia de su conducta, e igualmente, cuando claramente conoce que el resultado sucederá como consecuencia de su con-

complicidad o asocio de terceros, con la intención de causarle dicha pérdida al asegurado".

13 Estas exclusiones están contempladas en las distintas versiones provenientes del mercado inglés. 
ducta, porque en esta última hipótesis el funcionario no considera la probabilidad del resultado sino que lo asume como cierto.

En ambas hipótesis, el empleado, de manera consciente, persigue causar daño a su empleador y, por tanto, el amparo de infidelidad resultará afectado cuando, a través de una aparente omisión, se presenta una desviación de fondos de la entidad para facilitar su posterior apropiación por el mismo empleado o por terceros, como también cuando el empleado no cumple con las instrucciones que se le imparten por su empleador o por los clientes de la entidad y ejecuta ciertas operaciones que ocasionan pérdida a los clientes de la entidad o a ella misma.

Hipótesis de este tipo de pérdidas, se consideran las siguientes: la concesión de créditos de manera fraudulenta para lucrarse, al igual que las conductas burdamente negligentes, que resultan cercanas a actos ejecutados de manera deliberada para ocasionar una pérdida al banco o para obtener un beneficio pecuniario.

Pues bien, en la modificación del amparo de infidelidad de 200414, se suprimió la exigencia de "intención manifiesta" y en su lugar se expresa que el acto de infidelidad debía ejecutarse "con el activo y consciente propósito de causar al asegurado que soporte dicha pérdida"15; de esta manera se pretendió cerrar el paso a interpretaciones judiciales, según las cuales, el acto de infidelidad podía obedecer a mera negligencia, porque, en criterio de algunos tribunales americanos, la intención manifiesta no requería evidencia directa que el empleado deseaba ocasionar la pérdida al asegurado, porque aún en el evento en que el empleado no persistiera en la obtención de ese resultado, era consecuencia necesaria de la conducta misma de tal empleado y, por lo cual, resultaba satisfecho el requisito.

A través de ese cambio, también se quiso enfatizar que la cobertura exige que el empleado de manera consciente y deliberada desea el resultado y, por lo tanto, según distintos comentaristas, de esta forma se adoptó el nivel más alto de "intención" que adopta el Código Penal modelo de los Estados Unidos de América (Model Penal Code) ${ }^{16}$ y por tanto, proceder de manera consciente y deliberada implica que la persona actúe intencionalmente para obtener el resultado de su acción y que su objetivo consciente sea obtener dicho resultado, independientemente de la probabilidad de alcanzarlo.

\subsection{Amparo de infidelidad de empleados y dolo eventual}

Recapitulando, en frente de amparos de infidelidad de empleados, la expresión actos deshonestos o fraudulentos, ha sido interpretada por algunos tribunales americanos de

14 Corresponde a los textos que usualmente se encuentran en las versiones inglesas.

15 La expression en ingles es: with the active and conscious purpose to cause the insured to sustain such loss.

16 Keely, Michael y BLOCK, Luisa A. "Loan loss coverage under Financial Institutions Bond", American Bar Association, Chicago, 2007, páginas 54 y 55. 
forma amplia, pues aseveran que la palabra deshonestidad, incluye actos ejecutados por el empleado quebrantando sus deberes y obligaciones para con el banco, al igual que cualquier omisión deliberada para relevarse de los deberes propios de su cargo y han enfatizado que para qué una conducta pueda considerarse como deshonesta no requiere que tenga carácter punible de acuerdo con la ley ${ }^{17}$.

Y retomando la interpretación de algunos tribunales, respecto de la exigencia de "intención manifiesta" del empleado de causar una pérdida al asegurado o de obtener un beneficio económico, como ha quedado expuesto en páginas anteriores, esos pronunciamientos estimaron que no era necesario acreditar que el empleado deseaba decididamente que el asegurado sufriera la pérdida sino que resultaba suficiente con que el empleado percibiera o conociera que la pérdida era muy probable que ocurriera.

Bajo ese criterio, esos actos deliberados e intencionales de los empleados del asegurado, se ubican en fronteras muy próximas al dolo eventual, que conceptualmente, tiene su origen en el Derecho Penal y lo cual amerita algunas consideraciones al respecto $y$, particularmente, si en nuestro medio, puede resultar suficiente para desencadenar una pérdida cubierta bajo infidelidad de empleados18.

17 Horkovich, Robert M. op. cit., página 5. A este respecto, en las pólizas americanas es usual encontrar una cláusula de terminación o cancelación de la póliza, que establece que la cobertura se termina tan pronto como el asegurado tiene conocimiento que un empleado ha cometido actos deshonestos o fraudulentos en cualquier momento, ya sea durante el tiempo de servicio al asegurado o con anterioridad y sin importar si el tipo de deshonestidad, se encuentra cubierto bajo una póliza de fidelidad. Las Cortes han visto precisadas a limitar la aplicación de esta estipulación de terminación o cancelación a determinadas circunstancias, como son: no aplica cuando la deshonestidad era desconocida o fue ocultada al asegurado; no aplica cuando el asegurado no tuvo la oportunidad de despedirán empleados deshonestos; la mera sospecha o el rumor sobre actos deshonestos previos por parte de un empleado no es suficiente el asegurado debe tener evidencia sustancial de la deshonestidad previas para que pueda ser afectado por la cláusula de terminación y, finalmente, el conocimiento de prácticas de negocios ineficientes, errores, discrepancias o irregularidades contables, no constituyen descubrimiento de deshonestidad previa del empleado que dé lugar a la terminación de la cobertura.

18 Guillermo Cabanellas en su "Diccionario Enciclopédico de Derecho Usual" expresa lo siguiente: "El dolo penal admite varias modalidades: puede ser determinado, indeterminado o eventual. Es determinado cuando se encamina a una acción fija, precisa, concreta: así, un individuo quiere matar a otro, y lo consigue en efecto; el resultado coincide con su intención, con su voluntad y su plan. Es indeterminado cuando la intención criminal se manifiesta en propósito impreciso de causar el mal; tal es el caso de arrojar una bomba sobre una manifestación, donde se advierte indudable el deseo de matar a alguien, pero no se descubre el intento de que sea ésta o aquella persona en particular. Es eventual cuando el autor quiere un resultado, que aun no cierto, sea probable o posible; tal sería el caso de efectuar disparos, a baja altura, en una calle obscura y poco transitada. El dolo eventual configura la tenue frontera con la imprudencia". De manera que equipara el dolo eventual con la culpa con previsión y de ella expone que "... consiste precisamente en obrar de manera peligrosa, a pesar de la representación de un resultado posible, o también probable, 
Al respecto el Diccionario de la Real Academia de la Lengua, trae la siguiente acepción de dolo eventual: "dolo que concurre en el autor de un delito que no pretende cometerlo directamente, aunque ha considerado su posibilidad como resultado de su acción".

Por su parte, el artículo 22 del Código Penal colombiano, al definir el dolo dispone: "La conducta es dolosa cuando el agente conoce los hechos constitutivos de la infracción penal y quiere su realización. También será dolosa la conducta cuando la realización de la infracción penal ha sido prevista como probable y su no producción se deja librada al azar". Éste último aparte de la disposición, consagra el dolo eventual y, según el cual, el agente asume como probable la realización de la conducta tipificada en la ley penal, persiste en su proceder y deja al azar la producción de dicho resultado.

Por esta razón, se asevera que el dolo eventual se ubica en terrenos próximos a la culpa consciente, aunque tales conceptos no son equivalentes, como quiera que en el dolo eventual, el sujeto desde el punto de vista cognoscitivo, evalúa tanto la previsibilidad como la probabilidad de las consecuencias de su conducta19, el autor advierte una alta probabilidad que se produzca el resultado y se torna indiferente respecto de las resultas de esta. En la denominada culpa consciente, la persona alcanza a prever la posibilidad del daño a través de su conducta pero confía imprudentemente en poder evitarlo, “...la producción del resultado reconocida por el sujeto es muy lejana, siendo, por tanto, indiferente la actitud interna del sujeto frente al hipotético resultado" ${ }^{20}$

Respecto al contenido y extensión del dolo eventual, la Sala de Casación Penal de la Corte Suprema de Justicia, en sentencia de 25 de agosto de 2010, proceso 32964, M.P. José Leonidas Bustos Martínez, precisó que en la ley 599 de 2000, el legislador acogió la denominada teoría de la representación respecto del dolo eventual, lo cual implica que, el aspecto cognitivo se refiere a la probabilidad de obtener un resultado antijurídico y no al resultado mismo, que esa probabilidad de realización debe darse en el plano de lo concreto, vale decir, frente a la situación de riesgo específica y que el hecho de dejar librado al azar el resultado, involucra el componente volitivo, es decir, "el sujeto decide actuar o continuar actuando, no obstante haberse representado la existencia en su acción de un peligro inminente y concreto para el bien jurídico, dejando el resultado librado al azar". ${ }^{21}$ Si bien, el artículo 63 del Código civil co-

como consecuencia de la acción..."(Editorial Heliasta S.R.L., 20ae edición, Buenos Aires, páginas 311 y 312).

19 Altavilla, Enrico "La Culpa", Editorial Temis, 4ạ. edición, Bogotá, 1999, pág. 80 y ss.

20 Díaz, María del Pilar "El dolo eventual", Tirant Lo Blanch, Sevilla, 1994, página 23.

21 En esa oportunidad expuso la Corte: "El dolo ha sido definido tradicionalmente como la simbiosis de un conocer y un querer, que se ubica en la vertiente interna del sujeto, en su universo mental. En materia penal se dice que actúa dolosamente quien sabe que su acción es objetivamente típica y quiere su realización.

"De acuerdo con esta definición, alrededor de la cual existe importante consenso, el dolo se integra de dos elementos: Uno intelectual o cognitivo, que exige tener conocimiento o conciencia de los elementos objetivos del tipo penal respectivo. Y otro volitivo, que implica querer realizarlos. 
"Estos componentes, no siempre presentan los mismos grados de intensidad, ni de determinación. Ello, ha dado lugar a que la doctrina dominante distinga, en atención a la fluctuación de estos aspectos, tres clases de dolo: El directo de primer grado, el directo de segundo grado y el eventual.

"El dolo directo de primer grado se entiende actualizado cuando el sujeto quiere el resultado típico. El dolo directo de segundo grado, Ilamado también de consecuencias necesarias, cuando el sujeto no quiere el resultado típico pero su producción se representa como cierta o segura. Y el dolo eventual, cuando el sujeto no quiere el resultado típico, pero lo acepta, o lo consiente, o carga con él, no obstante habérselo representado como posible o probable.

"En todos los eventos es necesario que concurran los dos elementos del dolo, el cognitivo y el volitivo, pero en relación con este último sus contenidos fluctúan, bien porque varía su sentido o porque su intensidad se va desdibujando, hasta encontrarse con las fronteras mismas de la culpa consciente o con representación, que se presenta cuando el sujeto ha previsto la realización del tipo objetivo como probable (aspecto cognitivo), pero confía en poder evitarlo.

"En estas específicas fronteras es que surge el problema jurídico que hoy ocupa la atención de la Sala: definir si el tribunal acertó al ubicar la conducta del procesado dentro del marco del dolo eventual como modalidad del tipo subjetivo, o si esta decisión es equivocada, y la categoría llamada a regular el caso es la culpa consciente o con representación.

"Las dificultades surgen de sus similitudes estructurales. Tanto en el dolo eventual como en la culpa con representación o consciente el sujeto no quiere el resultado típico. Y en ambos supuestos el autor prevé la posibilidad o probabilidad que se produzca el resultado delictivo. "Por lo que la diferencia entre una y otra figura termina finalmente centrándose en la actitud que el sujeto agente asume frente a la representación de la probabilidad de realización de los elementos objetivos del tipo penal.

"Muchos han sido los esfuerzos que la doctrina ha realizado con el fin de distinguir el dolo eventual de la culpa consciente o con representación, y variadas las teorías que se han expuesto con ese propósito, pero las más conocidas, o más sobresalientes, o las que sirven generalmente de faro o referente para la definición de este dilema, son dos: la teoría de la voluntad o del consentimiento y la teoría de la probabilidad o de la representación.

"La teoría de la voluntad o del consentimiento hace énfasis en el contenido de la voluntad. Para esta teoría la conducta es dolosa cuando el sujeto consiente en la posibilidad del resultado típico, en el sentido de que lo aprueba. Y es culposa con representación cuando el autor se aferra a la posibilidad de que el resultado no se producirá.

"La teoría de la probabilidad o de la representación enfatiza en el componente cognitivo del dolo. Para esta teoría existe dolo eventual cuando el sujeto se representa como probable la realización del tipo objetivo, y a pesar de ello decide actuar, con independencia de si admite o no su producción. Y es culposa cuando no se representa esa probabilidad, o la advierte lejana o remota.

"Lo decisivo para esta teoría, en palabras de MIR PUIG, es el grado de probabilidad del resultado advertido por el autor. Aunque las opiniones se dividen a la hora de determinar exactamente el grado de probabilidad que separa el dolo de la culpa, existe acuerdo en este sector en afirmar la presencia de dolo eventual cuando el autor advirtió una gran probabilidad de que se produjese el resultado, y de culpa consciente cuando la posibilidad de éste, reconocida por el autor, era muy lejana. No importa la actitud interna del autor — de aprobación, desaprobación o indiferenciafrente al hipotético resultado, sino el haber querido actuar pese a conocer el peligro inherente a la acción ${ }^{7}$ 
"Si para la teoría del consentimiento —afirma RAMON RAGUÉS I VALLÉS- el centro de gravedad lo ocupa la relación emocional del sujeto con el resultado, en los planteamientos de la teoría de la probabilidad pasa a ocuparlo la conducta peligrosa, que el sujeto debe conocer como tal, sin que sea necesaria actitud emocional de ninguna clase.

"Como puede verse -continúa diciendo el autor- la teoría de la probabilidad pone el acento en una cuestión motivacional, pero se diferencia de la teoría del consentimiento, en que esta última entra a valorar los deseos o intenciones del sujeto, mientras que los defensores de la teoría de la probabilidad se limitan a constatar un déficit de motivación del sujeto sin que importen sus causas (en palabras de LAGMAN, la representación de la probabilidad del resultado no aporta un motivo contrario a la ejecución de la acción). ${ }^{8}$

"Hasta el año 2001 la legislación colombiana se mantuvo fiel a los postulados de la teoría del consentimiento, como estructura dogmática que busca explicar la frontera entre el dolo eventual y la culpa con representación ${ }^{9}$. Pero en la Ley 599 de 2000, tomó partido por la teoría de la representación, al definir el dolo eventual el los siguientes términos: "también será dolosa la conducta cuando la realización de la infracción penal ha sido prevista como probable y su no producción se deja librada al azar. Sobre esta variación, dijo la Corte,

(...)

"Desde ahora, es importante precisar que la representación en esta teoría (aspecto cognitivo) está referida a la probabilidad de producción de un resultado antijurídico, y no al resultado propiamente dicho, o como lo sostiene un sector de la doctrina, la representación debe recaer, no sobre el resultado delictivo, sino sobre la conducta capaz de producirlo, pues lo que se sanciona es que el sujeto prevea como probable la realización del tipo objetivo, y no obstante ello decida actuar, con total menosprecio de los bienes jurídicos puestos en peligro.

"La norma penal vigente exige para la configuración de dolo eventual la confluencia de dos condiciones, (i) que el sujeto se represente como probable la producción del resultado antijurídico, y (ii) que deje su no producción librada al azar.

"En la doctrina existe consenso en cuanto a que la representación de la probabilidad de realización del tipo delictivo debe darse en el plano de lo concreto, es decir, frente a la situación de riesgo específica, y no en lo abstracto. Y que la probabilidad de realización del peligro, o de producción del riesgo, debe ser igualmente seria e inmediata, por contraposición a lo infundado y remoto.

"Dejar la no producción del resultado al azar implica, por su parte, que el sujeto decide actuar o continuar actuando, no obstante haberse representado la existencia en su acción de un peligro inminente y concreto para el bien jurídico, y que lo hace con absoluta indiferencia por el resultado, por la situación de riesgo que su conducta genera.

"Dejar al azar es optar por el acaso, jugársela por la casualidad, dejar que los cursos causales continúen su rumbo sin importar el desenlace, mantener una actitud de desinterés total por lo que pueda ocurrir o suceder, mostrar indiferencia por los posibles resultados de su conducta peligrosa, no actuar con voluntad relevante de evitación frente al resultado probable, no asumir actitudes positivas o negativas para evitar o disminuir el riesgo de lesión que su comportamiento origina.

"La voluntad de evitación y la confianza en la evitación son conceptos que tienen la virtualidad de excluir o reafirmar una u otra modalidad de imputación subjetiva, según concurran o no en el caso específico. El primero implica un actuar. El segundo, la convicción racional de que el resultado probable no se producirá. Si existe voluntad de evitación, se excluye el dolo eventual, pero no la culpa con representación. Si existe confianza en la evitación, y esta es racional, se reafirma la culpa con representación y se excluye el dolo eventual. 
lombiano, define la culpa grave como "... no manejar los negocios ajenos con aquel cuidado que aún las personas negligentes o de poca prudencia suelen emplear en sus negocios propios" y la misma disposición añade que "Esta culpa en materias civiles equivale al dolo", tradicionalmente en el ámbito civil, la connotación del dolo obedece al propósito deliberado, directo y reflexivo de inferir daño, y esa equiparación entre la culpa grave (que comprende la culpa consciente ${ }^{22}$ ) y el dolo, que consagra la disposición en cita, se ha entendido en la doctrina y la jurisprudencia patrias, que no tiene otra connotación distinta a aquella de imponer al deudor la indemnización de todos los perjuicios derivados de su incumplimiento23, por lo que en el estado actual de la ciencia jurídica, en nuestro medio, el dolo eventual no tendría la virtualidad de desencadenar una pérdida amparada bajo infidelidad de empleados.

"Las dificultades que suscita la comprobación directa de los componentes internos del dolo eventual (cognitivo y volitivo), han obligado a que su determinación deba hacerse a través de razonamientos inferenciales, con fundamento en hechos externos debidamente demostrados, y en constantes derivadas de la aplicación de reglas de la experiencia, como el mayor o menor grado de peligrosidad objetiva de la conducta, «mayor o menor contenido de peligro de la situación de riesgo, o la calidad objetiva del riesgo creado o advertido.

"Estos criterios de distinción, que la doctrina y la jurisprudencia abrazan cada vez con mayor asiduidad, no han sido ajenos a esta Corporación. En decisión de 2007, la Corte llamó la atención sobre la necesidad de examinar frente al dolo eventual los delitos de tránsito en los qué la creación del riesgo desbordaba las barreras de la objetividad racional y el sujeto actuaba con total desprecio por los bienes jurídicos que ponía en peligro".

22 En sentencia de junio 2 de 1958, La Corte Suprema de Justicia expresó: "Noción de la culpa. Es definida la culpa por la doctrina en los siguientes términos: "Hay culpa cuando el agente no previó los efectos nocivos de su acto, habiendo podido preverlos o cuando a pesar de haberlos previsto, confió imprudentemente en poderlos evitar.

"La culpa pues se presenta en dos casos:

“a) cuando el autor conoce los daños que pueden ocasionarse con un acto suyo, pero confió imprudentemente en evitarlos. Esta es la llamada culpa consciente y es desde luego la más grave. Así cuando alguien conociendo de los defectos de una máquina, antes de proceder a su reparación la emplea en una act6ividad en la esperanza de no perjudicar a otro, es responsable de culpa o negligencia consciente en razón del daño causado.

b) Cuando el autor no prevé el daño que puede causarse con un acto suyo, pero hubiera podido preverlo, dado su desarrollo mental y conocimiento de los hechos. Aquí se trata de una negligencia o culpa inconsciente. En el ejemplo anterior, el no conocer los defectos de una máquina hace al autor responsable de culpa inconsciente, pues una persona prudente debe examinar continuamente los instrumentos que emplea en una determinada actividad. "Conforme a esta definición, la culpa se condiciona a la existencia de un factor sicológico consistente en no haber previsto un resultado dañoso pudiéndose haber previsto, o en haberlo previsto y haber confiado en poder evitarlo"

(...)

"La culpa no es posible determinarla con base en el estado de cada persona; es necesario un criterio objetivo o abstracto, Este criterio abstracto aprecia la culpa teniendo en cuenta el modo de obrar de un hombre prudente y diligente considerado como arquetipo" ("Código Civil y legislación complementaria" ; Legis Editores S.A., Bogotá, página 28).

23 Ospina Fernandez, Guillermo “Régimen general de las obligaciones”, Editorial Temis Ltda, 4ae edición, Bogotá, 1987, página 115. 
Sin duda, es un hecho incuestionable que las realidades sociales colocan constantemente en evidencia la insuficiencia de los cánones legales ante ciertas circunstancias, lo cual torna exigente la labor de la jurisprudencia como fuente creadora de Derecho y quien usualmente resulta influenciada por los esfuerzos ya desplegados por algunos sectores de la doctrina. En la hora actual, el jurisconsulto chileno Pablo RODRIGUEZ GREZ propugna por una redefinición del dolo en materia civil, de tal manera que se extienda a cobijar no sólo los actos intencionales, sino también a aquellos en los cuales el sujeto considera la probabilidad de inferir daño con su proceder ${ }^{24}$.

En efecto, estima que como "el dolo (en la medida que éste sea considerado como la intención positiva de dañar (se alberga, por consiguiente, en el fuero interno de la persona, de lo cual se sigue que resulta imposible probarlo contra la voluntad del hechor", ante esta evidencia propugna por la objetivización del dolo civil y considera que: "lo cual se logra, por la vía interpretativa, por el hecho de desplazar la intencionalidad pura a la representación y la certeza o probabilidad del resultado. Ninguna duda puede asistirnos sobre que de esta manera damos a la ley una interpretación finalista que se afinca en la voluntad y el espíritu de la ley.

"Quien ejecuta una conducta, así sea una acción u omisión, conociendo la cadena causal que desemboca en un resultado dañino y, a ciencia y conciencia, acepta el resultado, generalmente en función de un beneficio propio, no puede ser tratado en el derecho sino como un sujeto "maligno", como dice la doctrina francesa, que causa el daño voluntariamente. En el mundo moderno la sola posibilidad de causar un daño es un antecedente suficiente para imponer al autor la más drástica sanción social "

Y añade: "Nuestra posición desplaza el elemento rector del dolo a la previsibilidad del daño, su representación consciente y su aceptación, en función, generalmente, de un lucro o beneficio patrimonial que no corresponde legítimamente al autor del daño. De esta manera queda abierta la posibilidad de que la víctima del dolo pueda acreditar, mediante el examen d la cadena causal, la posibilidad de que el autor se haya representado el resultado, siguiendo de ello la aceptación de la consecuencia dañosa" ( Se destaca). ${ }^{25}$

24 El doctrinante chileno Enrique Barros Bourie formula las siguientes reflexiones: "El dolo eventual plantea diversas dificultades de aplicación en materia civil. Ante todo, porque la mera representación y aceptación del daño no son constitutivos de culpa per se, sino sólo en la medida que se incurre en contravención a un estándar de cuidado debido. La situación más típica de dolo eventual en el derecho civil se produce cuando puede asumirse que el autor del daño ha aceptado voluntariamente el daño, atendido lo probable y peligrosos del resultado. Pero, en este punto, el dolo de nuevo se encuentra con la culpa grave: es indiferente si el autor del daño aceptó ese resultado altamente riesgoso (caso en el cual habrá culpa intencional ) o si en grave desconsideración del interés ajeno simplemente lo ignoró (como en el caso de la culpa grave)". ("Tratado de responsabilidad extracontractual", Editorial Jurídica de Chile, Santiago, 2009, página 160).

25 "Responsabilidad extracontractual", Editorial Jurídica de Chile, Santiago de Chile, 2002, página 167. 
De alcanzarse esa objetivización del concepto de dolo en el campo civil, el amparo de infidelidad de empleados bajo la póliza global bancaria, comprendería aquellos supuestos en que los funcionarios de la entidad desatienden instrucciones de clientes, donde, evidentemente, existe negligencia ante la omisión consciente y deliberada de dejarlas de lado, como también resulta manifiesta la imprudencia, por cuanto con ese proceder el funcionario omite considerar, a pesar de su idoneidad profesional y el conocimiento de los riesgos propios de las operaciones que desarrolla, que puede ocasionar detrimento al cliente, de manera directa y, por supuesto, de manera refleja, a la entidad para la cual labora y por si fuera poco, también se configura una clara inobservancia de las cánones propios del manejo de dineros e inversiones ajenas, en lo cual omite voluntariamente ajustar su conducta a tales parámetros con una clara indiferencia ante los resultados que pueda generar su proceder.

Atendiendo a esos rasgos de la conducta del empleado, se trataría de actos deliberados que, por razón de la imprudencia, negligencia e inobservancia de reglamentos, es evidente la intención manifiesta de causar daño a su empleador.

A este respecto resultan de interés el laudo de 24 de octubre de 2012 de Proyectar Valores vs. Chubb de Colombia y el de 9 de diciembre de 2014 de de Asesorías e Inversiones S.A. vs. AIG Colombia.

El común denominador de las reclamaciones obedeció a que los asegurados, sociedades comisionistas de bolsa, reclamaron las pérdidas ocasionadas por sus empleados, resultantes del manejo de fondos de clientes de la entidad y en lo cual éstos desatendieron las instrucciones que les habían sido impartidas por los clientes y procedieron de manera inconsulta ${ }^{26}$.

26 El primero de los casos mencionados, las pretensiones de la demanda se formularon bajo el amparo de responsabilidad civil profesional y subsidiariamente bajo la cobertura de infidelidad de empleados. En este caso, el incumplimiento de las instrucciones impartidas por los clientes, por parte de los funcionarios de la firma comisionista, generaron un resultado adverso, por lo cual la firma comisionista se comprometió a reconocer un determinado número de acciones que debían tener los clientes en su portafolio y lo cual le representó una pérdida de consideración. Formulada reclamación bajo la póliza de seguro objetada por considerar la aseguradora que se trata de actos de infidelidad. En el curso del proceso arbitral, al contestar la demanda, la aseguradora adujo que no se encontraba afectado el amparo de responsabilidad civil profesional como tampoco el de infidelidad de empleados. El tribunal de arbitramento estimó que los amparos son excluyentes porque exigen que se cumplan las exigencias de los mismos; en este sentido, el amparo de responsabilidad civil profesional excluye la deshonestidad, fraude o dolo del asegurado o de cualquier ejecutivo o empleado del asegurado y en el caso materia de decisión, la forma proceder de los empleados de la comisionista fue calificada por el tribunal como deshonesta y como una acepción del dolo es quien obra en conciencia del daño que con su acción u omisión puede ocasionar, concluyó que los empleados habían obrado dolosamente. Sin embargo, ante esa hipótesis se encontró con falta de fundamentación fáctica y que respecto del amparo de infidelidad no se encontraba demostrado que los empleados hubieran obtenido una ganancia financiera como quiera 
En ambos casos, la decisión de los paneles arbitrales fue similar, vale decir, se consideró que el amparo de responsabilidad profesional excluía los actos deshonestos o fraudulentos de los empleados, pero no resultaba afectada la cobertura de infidelidad de empleados, pues si bien había sido acreditado el proceder deshonesto y fraudulento de los empleados del asegurado, no se había comprobado la ganancia o lucro financiero obtenido por éstos, como lo exigía el clausulado KFA 81 de tales coberturas de infidelidad ${ }^{27}$.

que las podas la descartaban al considerar que las pérdidas sufridas por la comisionista habían obedecido a malas inversiones.

En el segundo caso, los empleados de la firma comisionista realizaron operaciones no autorizadas por algunos de los clientes. La firma comisionista indemnizó a los clientes que resultaron afectados. El amparo de infidelidad empleados exigía que los actos dolosos o fraudulentos para cometidos por estos con el ánimo de efectuarlos y que resultaran en un lucro deshonesto para ellos; exigencia que las pretensiones subsidiarias de la demanda se solicitó su declaratoria de abusiva y por tanto de ineficaz. En el curso del proceso se estableció que los empleados obtuvieron bonificaciones por lo que en la demanda se adujo que las operaciones dolosas de los empleados no podían ser reputarse como desarrollo normal de tales operaciones porque habían sido ejecutadas sin autorización de los inversionistas y en este sentido las bonificaciones no podían considerarse como obtenidas en el ejercicio normal de sus labores. En su decisión, el tribunal enfatizó que: "Queda absolutamente claro, al punto de parecer redundante, que los actos objeto de cobertura deben ser totalmente intencionales. Ellos no podrán ser producto de un actuar meramente negligente o imprudente; se requiere absoluta y plena conciencia de su realización. El deseo de materialización de tales actos debe hallarse presente en su artífice, para que puedan enmarcarse dentro de las líneas conceptuales trazadas" y puntualizó que: "...el dolo aquí se hace referencia debe entenderse desde su acepción civil y no en su conceptualización penal". En relación con la cláusula de infidelidad de empleados, el Tribunal consideró que no era ambigua, pues señalaba de manera clara los requisitos que se exigían para la configuración del siniestro y con relación a que la exigencia de un lucro financiero en esta estipulación resultara abusiva y por lo tanto ineficaz, concluyó que la luz del artículo 11 de la ley 1328 y de la Circular 039 de la Superintendencia Financiera, no correspondía a ninguna de las cláusulas prohibidas y, de otra parte, no apreciaba que generará un desequilibrio injustificado sino que obedecía a la facultad que tiene el asegurador de delimitar los riesgos que asume a su cargo en virtud del artículo 1056 del estatuto mercantil y que por tratarse de una facultad legal, no contradecía la buena fe contractual. Concluyó que en el caso materia estudio, los actos ejecutados por los empleados habían sido intencionales y no fruto de descuido o negligencia; sin embargo, como el asegurado no había acreditado el lucro deshonesto que hubieran tenido o que se hubieran apoderado de dinero correspondiente a sumas invertidas por los inversionistas. Si bien, entre las estipulaciones de la póliza no estaba contemplada la exclusión denominada "transacciones no autorizadas" (que coloca por fuera del amparo las operaciones que se lleven a cabo sin la autorización de los clientes), el tribunal concluye que, para que las pérdidas resultaran amparadas por la póliza, se requería que obedecieran a actos deshonestos o fraudulentos de los empleados del asegurado y que se hubiera obtenido por parte de éstos un lucro financiero.

27 En el clausulado NMA 3000 de responsabilidad profesional bancaria, se otorga amparo respecto de actos deshonestos y fraudulentos de empleados del asegurado, cuando 


\subsection{Otros amparos de la póliza}

En las modificaciones de la forma americana No. 24 en el año 2004, en cuanto al amparo de predios, se excluyó el vandalismo del amparo de actos malintencionados y, en el amparo de tránsito, se enfatizó que la movilización sólo podría efectuarse a través de un empleado de una compañía transportadora y los bienes debían encontrarse en tránsito y no depositados en los predios de la compañía transportadora, de tal forma que se hizo claridad en que el amparo de tránsito opera respecto de la movilización de los bienes asegurados, pero en ningún caso se extiende la cobertura a las permanencias que puedan presentarse en los respectivos trayectos.

A continuación, con el ánimo de dar una panorámica de las tendencias que se identifican en la hora actual en la gestión de este tipo de productos, se examinan algunos de los aspectos de la póliza global bancaria que han despertado controversia.

\section{El descubrimiento de pérdidas: precisiones sobre los presupuestos para su configuración}

Este tipo de pólizas operan sobre la base de descubrimiento de pérdidas ${ }^{28}$ y claro está, lo que constituye descubrimiento para efectos de la afectación de la respectiva póliza,

éstos ocasionen detrimentos patrimoniales a terceros, pero supeditado a que se acredite el beneficio pecuniario obtenido por el empleado o empleados del asegurado. Esta cobertura aparece por primera vez en esta versión pues no se contemplaba en esta clase de clausulados.

28 En el caso colombiano, acoger esta modalidad de operación de las pólizas que ampararan riesgos de la actividad financiera, requirió de una autorización especial por parte del legislador, la cual se materializó en el artículo 23 de la ley 35 de 1993 y en el numeral 3o del artículo 185 del Estatuto Orgánico del Sistema Financiero, vale decir, en materia de riesgos propios de la actividad financiera es dable amparar los hechos pretéritos bajo el supuesto que éstos resultan desconocidos para tomador y asegurador.

El artículo 23 de la ley 35 de 1993 dispuso: "En los seguros que tengan por objeto el amparo de los riesgos propios de la actividad financiera, se podrán asegurar, mediante convenio expreso, los hechos pretéritos cuya ocurrencia es desconocida por tomador y asegurador" (Se destaca).

Por su parte, el articulo 185 del Estatuto Orgánico del Sistema Financiero reiteró esa permisión, así: “...3. Riesgos de la actividad financiera. En los seguros que tengan por objeto el amparo de los riesgos propios de la actividad financiera, se podrán asegurar, mediante convenio expreso, los hechos pretéritos cuya ocurrencia es desconocida por tomador y asegurador" (Se destaca).

Finalmente, el inciso 1ํ del artículo 4을 de la ley 389 de 1.997, estableció: "En el seguro de manejo y riesgos financieros y en el de responsabilidad la cobertura podrá circunscribirse al descubrimiento de pérdidas durante la vigencia, en el primero, y a las reclamaciones formuladas por el damnificado al asegurado o a la compañía durante la vigencia, en el segundo, así se trate de hechos ocurridos con anterioridad a su iniciación. 
ha sido materia de discusión en tribunales americanos y es así como, en defecto de una estipulación en la póliza que lo defina, se han esgrimido distintas tesis. ${ }^{29}$

En los Estados Unidos de América, los tribunales para determinar cuándo ocurre el descubrimiento de una pérdida, han acudido a tests que combinan factores objetivos y subjetivos ${ }^{30}$.

En el criterio subjetivo, se exige que, con base en el conocimiento del asegurado de los hechos en un momento determinado, éste pueda efectuar inferencias razonables que lo lleven a colegir que se ha presentado una circunstancia que es materia de amparo bajo la respectiva póliza.

Por su parte, el criterio objetivo considera que existe descubrimiento si con base en la percepción de los hechos, una persona razonable colocada en las mismas circunstancias, concluiría que ha sufrido una pérdida que puede ser materia de amparo bajo la póliza global bancaria.

Bajo este segundo criterio, se formula la salvedad que la mera sospecha no constituye descubrimiento y en este sentido, si los hechos conocidos conducen a una persona razonable a asumir que existe una pérdida, pero como no cuenta con los detalles sobre el monto involucrado o en relación con la manera específica en que se cometió la defraudación, se trataría tan solo de una sospecha.

En otras palabras, no basta que el asegurado conozca hechos que lo conduzcan a considerar que podría existir un posible desfalco o defraudación, por cuanto esto no satisface las exigencias del criterio objetivo, vale decir, ante una sospecha de parte del asegurado como consecuencia del conocimiento de hechos que indicarían la posible

29 En materia de descubrimiento la forma americana número 24 establece que: "Discovery occurs when the insured learns of fracts which would cause a reasonable person to believe a loss has been or will be incurred. In the case of third party claims, dioscovery occurs when the insured receives notice of aclaim, if true, would create a covered loss" y en cuanto a la definición de descubrimiento, la misma estipulación exige que el asegurado "...,first becomes aware of facts which would cause a reasonable person to assume that a loss has been or will be incurred, even though the exact amount or details of loss may not then be known. Discovery also occurs when the insured receives notice of an actual or potential claim in which it is alleged that the insured is liable to a third party underr circumstances which, if true, would constitute aloss under this bond" y claro está, esa definición no está exenta de posiciones antagónicas por cuanto para algunos esa definición se encuentra más próxima a la "pura sospecha" que al "conocimiento", mientras que otros opinan exactamente lo contrario. Sin duda, ese tipo de estipulaciones pretenden imponer al asegurado la obligación de actuar con la mayor diligencia ante la sospecha que ha sido afectado por un acto de infidelidad, de tal forma que pueda implementar correctivos de manera inmediata que permitan mitigar la pérdida e identificar las acciones que se vienen ejecutando y los artífices de las mismas.

30 Keely, Michael. Duffy Sean "Handling fidelity bond claims", $2^{\text {nd }}$ Edition, editors American Bar Association, 2005, Chicago, Illinois, USA. 
comisión de una conducta deshonesta de sus empleados y que le haría incurrir en una pérdida, el asegurado estaría obligado a efectuar las correspondientes indagaciones (duty of enquiry), es decir, investigar las circunstancias que llegaron a su conocimiento, para confirmar o desvirtuar esa sospecha, esas inferencias preliminares que hubiera podido realizar.

De todas maneras, se formula la salvedad que la existencia de una investigación ex post que conduzcan al asegurado al convencimiento que efectivamente existe un fraude, no hacen que esa sospecha inicial (ex ante) pueda catalogarse posteriormente como descubrimiento de la pérdida.

En consecuencia, la mera sospecha se estima insuficiente para que constituya descubrimiento, por lo que la inquietud que surge es sobre el grado de percepción, el estado de la mente que puede llegar a constituir descubrimiento y, por ende, las exigencias que deban satisfacerse para que pueda hablarse de la existencia de una pérdida potencial.

Según explica un especialista en la materia, los tribunales han intentado aclarar la distinción existente sospecha y conocimiento, bajo el entendido que descubrimiento es sinónimo de obtener información, de tal manera que cuando el asegurado percibe hechos (learn of facts) que constituyen una deshonestidad potencial de un empleado, su sospecha inicial puede transformarse, en virtud de las respectivas indagaciones, en conocimiento, lo que a su turno configura "descubrimiento" para el asegurado ${ }^{31}$.

En otras palabras, para dilucidar cuando se consolida el conocimiento por parte del asegurado, el análisis debe orientarse a identificar los hechos que conocía el asegurado en un momento en particular y, con base en esos hechos, establecer que conclusiones extraería de ellos una persona razonable y, si ese conocimiento o sospecha de fraude daba lugar o no a un deber de indagar (duty of enquiry).

Bajo este criterio objetivo, que es el predominante, el asegurado está obligado a dar aviso de la pérdida, cuando tenga conocimiento suficiente de los hechos en un momento determinado; no basta la mera sospecha de la existencia de hechos, sino un grado de percepción que harían que una persona prudente y cuidadosa pudiera acusar a otra de fraude o deshonestidad, con la salvedad puesta de relieve por otros pronunciamientos, que el conocimiento de todos los pormenores de la pérdida no es necesario, basta con que el asegurado conozca hechos que sean suficientes para que una persona razonable estime que las circunstancias de la pérdida corresponden a la cobertura de la póliza ${ }^{32}$.

31 En el caso de Nike Inc vs. Northwestern Indemnity Co. (2000), se cita que el tribunal adujó que el descubrimiento tiene lugar cuando el asegurado logra suficiente conocimiento, más allá de una mera sospecha, que justificaría que una persona prudente y razonable crea que ha tenido lugar, un acto de deshonestidad y una pérdida bajo la cobertura de la póliza.

32 Connolly, Mark Mark A "Procastinating principals: discovery and notice of claim under fidelity bonds and commercial crime policies", Thirteenth Annual Southern Surety and Fidelity Claims Conference, Charleston, April 25-26, 2002 página 5. 
Evidentemente, los detalles de la extensión de la pérdida sufrida por el asegurado, las operaciones involucradas, la forma como fue perpetrada y descubierta la pérdida no son conocidos, por lo regular, sino hasta el momento en el cual se presenta la reclamación, todo lo cual dependerá por supuesto, de la complejidad de las circunstancias fácticas, número de operaciones realizadas y el período en que hubieren sido efectuadas. ${ }^{33}$

33 En el Laudo arbitral de ISS (En Liquidación) vs. La Previsora S.A. de 8 de octubre de 2015 (árbitros: Adriana López Moncayo, José Guillermo Peña González y Jorge Eduardo Narváez Bonnet),al abordar lo relativo al conocimiento que es exigible al asegurado en frente de una defraudación materia de una póliza de manejo, se expresa lo siguiente: “... el Tribunal considera que el asegurado tiene conocimiento de los hechos desencadenantes del siniestro, en un caso como el que es materia de examen en este trámite arbitral, cuando adquiere certeza de la defraudación, de la época de ocurrencia de los hechos, del instante en que se materializaron, lo que sólo se produce, una vez se cumplen las labores de investigación y de confrontación de los registros y por lo mismo, lo que se torna relevante es el instante en que el asegurado aprehende esos detalles, aunque las apropiaciones de fondos efectivamente hubieran podido ocurrir en un tiempo anterior.

"Dicho de otra manera, el conocimiento de las circunstancias que constituyen el siniestro, se presenta cuando el asegurado sabe de la ocurrencia de los hechos con certeza razonable". (...)

"Para el Tribunal, el conocimiento, que exige en materia de prescripción ordinaria el artículo 1081 del estatuto mercantil, implica la percepción directa de los hechos por parte del asegurado y tratándose, como en este caso, de una cobertura de ocurrencia, conllevaría que el asegurado pudiera determinar la materialización de los hechos que son objeto de amparo y, por supuesto, ese conocimiento debe obedecer a circunstancias de carácter fáctico u objetivo que le permitan establecer de manera razonable que ha sufrido una pérdida.

"Es decir, no basta la mera percepción de los hechos por el asegurado a través de los sentidos, no debe tratarse de una mera conjetura o de una sospecha y por tanto, en frente de la cobertura de un seguro de manejo, será menester que actúe con base en ese conocimiento preliminar sobre una eventual defraudación, previa indagación o investigación y examen de esos hechos que percibe, que le permitan confirmar o desvirtuar esa sospecha, vale decir, obtener detalles de la manera cómo se llevó a efecto la defraudación que le permitan inferir, de manera objetiva y razonable, que la pérdida se ha presentado como consecuencia de un proceder de aquellos calificados en la respectiva póliza como detonantes de la protección del asegurador.

"En otras palabras, podría predicarse conocimiento del asegurado, tan pronto éste se encuentre capacitado para determinar el posible grado de complejidad de las maniobras defraudatorias, el número de actos u operaciones ejecutadas y el período utilizado para ese efecto.

"A juicio del Tribunal, una de las acepciones del vocablo conocer que trae el diccionario de la Real Academia de la Lengua es: "Averiguar por el ejercicio de las facultades intelectuales la naturaleza, cualidades y relaciones de las cosas"; con fundamento en expediente interpretativo que autoriza el artículo 823 del estatuto mercantil, por lo que cuando el Tribunal expresa que el asegurado debe haber alcanzado un grado de certeza razonable, significa que la percepción de la realidad debe haber sido objeto de investigación y de algún grado de comprobación, para disipar cualquier duda y así evitar que el asegurado emita un juicio con base en apariencias o meras conjeturas". 
Ante este panorama, en la praxis americana, un aspecto crucial en las reclamaciones bajo el amparo de infidelidad de empleados, será el de establecer cómo fue descubierta la pérdida y cuando se materializó ese descubrimiento; circunstancia esta última que, en línea de principio, ocurrirá cuando se concluyan las investigaciones adelantadas por el asegurado; si bien, en algunos casos, a pesar de esas investigaciones, los detalles sobre las particularidades de la defraudación pueden permanecer ocultos, aún en aquellos supuestos en que el asegurado hubiese desplegado sus pesquisas de la manera más diligente posible.

En otras ocasiones, tales particularidades serán dilucidadas a través de inferencias con base en ciertos hechos conocidos y comprobados y, claro está, después de evaluar las circunstancias y las hipótesis de posibles vías para la vulneración de los controles que tenía en vigor el asegurado.

De otra parte, en cuanto a los caracteres de ese hallazgo, el descubrimiento podría ser súbito o repentino o el resultado del conocimiento gradual o paulatino de irregularidades que, como consecuencia de indagaciones o investigaciones más profundas, llevan a la conclusión que el empleado ha sido deshonesto y que, como consecuencia de ello, el asegurado ha sufrido una pérdida o que muy probablemente la sufrirá34.

En conclusión, no corresponde al grado de conocimiento que constituye descubrimiento de una pérdida, en los términos de la póliza, que el asegurado tenga conocimiento de hechos que conduzcan a inferir otros hechos y que sean tales inferencias las que conduzcan a evidenciar que existe un faltante o una defraudación. De igual manera, existe consenso que la mera sospecha de la deshonestidad de un empleado no constituye descubrimiento para los efectos de la cobertura de infidelidad ${ }^{35}$.

34 Es evidente que en casos de cierta complejidad, los detalles de la extensión de la pérdida sufrida por el asegurado, las operaciones involucradas, la forma como fue perpetrada y descubierta, no son conocidos sino posteriormente cuando amplias investigaciones se consuman; en muchas ocasiones, al momento en que la entidad financiera formula reclamo a la aseguradora, desconoce detalles sobre el modo de comisión de la defraudación, porque ese cabal conocimiento de los hechos dependerá de la complejidad de las circunstancias fácticas, el número de operaciones realizadas, el período en que hubieren sido efectuadas y por ello, puede aseverarse que, en la praxis, en este tipo de reclamos, es evidente que esa carta de reclamación da inicio a un proceso de comprobación de las circunstancias y del monto de la pérdida que se va nutriendo con el desarrollo de las investigaciones adelantadas por el mismo asegurado o por las autoridades; indagaciones que pueden tomar meses y aún períodos mucho más extensos, por lo que ante la proyección en el tiempo de ese proceso de reclamación ante la aseguradora, en el caso colombiano cobra especial importancia el requerimiento escrito previsto en el artículo 94 del Código General del Proceso, como un mecanismo idóneo para interrumpir el discurrir de los términos de prescripción bajo el contrato de seguro. 
En otros términos, el descubrimiento exige un estado subjetivo de parte del asegurado respecto del conocimiento de algunos hechos que necesariamente conducen a concluir que ha ocurrido una pérdida como resultado de la deshonestidad de un empleado, aunque el monto exacto de la pérdida o los detalles de la misma no se conozcan en ese momento.

En este sentido los tribunales americanos han desechado la interpretación que el descubrimiento debe ocurrir en un tiempo anterior, vale decir, en aquel momento en que el asegurado ha debido conocer de la defraudación y que, correspondería aquel en que un asegurado diligente ha debido tener conocimiento que algo no estaba bien (something was wrong).

Como excepción a la regla de descubrimiento se ha reconocido la denominada "doctrina de la dominación adversa" ("The adverse domination doctrine") y según la cual un asegurado se encuentra imposibilitado para descubrir los actos deshonestos de un empleado y dar aviso oportuno del siniestro porque el funcionario encargado de dar ese aviso es el mismo funcionario deshonesto.

En esos casos se ha expresado que el funcionario deshonesto "adversamente domina" al asegurado, porque actúa de una forma tal que es adversa o contraria a los intereses del asegurado y bajo esas circunstancias el conocimiento no le puede ser imputado a la entidad asegurada hasta tanto el descubrimiento de esos actos deshonestos sea efectuado por un funcionario ajeno a la maniobra ${ }^{36}$.

Finalmente, este aspecto relativo a determinar el momento del descubrimiento no es puramente académico o conceptual, por cuanto tiene distintas consecuencias, como son: determina la póliza a ser afectada y la cual corresponderá a la que se encuentre vigente al momento en que ese descubrimiento ocurra; la obligación de dar aviso del siniestro al asegurador de la póliza presumiblemente afectada, el discurrir de los términos de prescripción, entre otras.

\section{La supuesta abusividad de algunas estipulaciones de la póliza global bancaria}

\subsection{Consideraciones generales}

Ante el carácter de contrato de adhesión que, por lo general, se le endilga al contrato de seguro, apareja distintas consecuencias, como son: la prevalencia de las condiciones particulares del amparo sobre las generales, la proscripción de todo desequilibrio material en contra del tomador o asegurado y la prohibición expresa del mismo legislador de modificar algunas disposiciones en sentido contrario al tomador o asegurado ( Art. 1162, C. de Co.).

36 Horkovich, Robert M. "Insurance coverage for employee theft losses: a policyholder primer a commonly litigated issues", University of Memphis Law Review, September 2008, página 3. 
Además, como proyección de la tendencia moderna a la protección al consumidor, desde la ley 45 de 1990 se adoptaron disposiciones encaminadas a tutelar los derechos de los tomadores, de los asegurados y crear condiciones apropiadas para el desarrollo del mercado asegurador, así como una competencia sana de las instituciones que participan en él ${ }^{37}$.

Posteriormente, la Ley 1328 de 2009, estableció principios rectores para la protección del consumidor financiero y para ese efecto considero por tal: “....todo cliente, usuario o cliente potencial de las entidades vigiladas" (literal d, art. 2); precepto que al ser interpretado por la Corte Constitucional, se preciso que se adquiere ese carácter cuando la adquisición del bien o servicio va encaminado a satisfacer una "necesidad propia, no ligada a su actividad económica" ${ }^{38}$.

37 En desarrollo de tales principios, el Título III denominado "Trasparencia en las operaciones", el capítulo III se intitula protección a tomadores y asegurados, en el que, entre otras disposiciones, se consagraron algunas encaminadas a que las condiciones de las pólizas y las tarifas respondieran al régimen de libertad de competencia en el mercado de seguros. En el caso de las condiciones de las pólizas se reitero que debían acatar las disposiciones imperativas so pena de ineficacia, como también redactarse en tal forma que resultaran de fácil comprensión para el asegurado, por lo que los caracteres tipográficos debían ser fácilmente legibles y los amparos básicos y las exclusiones debían figurar, en caracteres destacados, en la primera página de la póliza (art. 44).

Las pólizas deben cumplir con diversas exigencias y es así, como en materia de contenido deben atender las disposiciones imperativas que le resulten aplicables so pena de ineficacia; redactarse de manera que resulten de fácil comprensión y donde los caracteres tipográficos sean fácilmente legibles e, igualmente, los amparos básicos y las exclusiones deben aparecer en caracteres destacados en la primera página de la póliza (art. 184 EOSF, modificado por el artículo 42 de la L. 795 de 2003).

38 El numeral 3o del artículo 5을 de la ley 1480 de 2011 ("Estatuto del consumidor"), define al consumidor en los siguientes términos: "Toda persona natural o jurídica que, como destinatario final, adquiera, disfrute o utilice un determinado producto, cualquiera que sea su naturaleza para la satisfacción de una necesidad propia, privada, familiar o doméstica y empresarial cuando no esté ligada intrínsecamente a su actividad económica. Se entenderá incluido en el concepto de consumidor el de usuario". La Corte Constitucional en sentencia C- 909 de 7 de noviembre de 2012, M.P. Nilson Pinilla, al ocuparse del análisis de exequibilidad del literal d) del artículo 2o de la ley 1328 de 2009 que contiene la definición de consumidor financiero, la acompaso con la prevista en la ley 1480 de 2001, como quiera que expresó que: "... ha de precisar esta Corte que la expresión "todo" converge en quien entrañe una relación de consumo ante las entidades vigiladas por la Superintendencia Financiera de Colombia, de manera que, como consumidor financiero, (i) refiere a un determinado sector de la economía, (ii) frente a la adquisición de un bien o servicio, para satisfacer una necesidad propia, no ligada intrínsecamente a su actividad económica, componentes que coetáneamente permiten establecer que, (iii) aunque no sea habitual consumidor financiero, ello no enerva ni impide que llegue a serlo, manteniéndose como potencial consumidor, que se materializará al mostrar interés por un bien o servicio, y (iv) lo será todo aquel vinculado de una u otra forma, directa o indirectamente, con las entidades vigiladas por razón del producto o servicio ofrecido y adquirido o por adquirir, propio de tal actividad económica". 
Tales postulados de protección al consumidor financiero, se refieren a la debida diligencia en el ofrecimiento de los productos, la libertad de elección de contrapartes en la celebración de los contratos, trasparencia e información cierta, suficiente y oportuna que le permita conocer adecuadamente sus derechos y deberes, responsabilidad de las entidades financieras en el trámite de quejas, manejo adecuado de los conflictos de interés por parte de éstas y la educación de los consumidores respecto de los productos y servicios ofrecidos.

El artículo 11 de la ley 1328, prohibió la utilización de cláusulas abusivas en las pólizas de seguro y, para ese efecto, contempló distintos supuestos, como son: aquellas que prevean o impliquen limitación o renuncia al ejercicio de los derechos de los consumidores financieros; inviertan la carga de la prueba en perjuicio del consumidor financiero; incluyan espacios en blanco, siempre que su diligenciamiento no esté autorizado detalladamente en una carta de instrucciones; cualquiera otra que limite los derechos de los consumidores financieros y deberes de las entidades vigiladas derivados del contrato, o exonere, atenúe o limite la responsabilidad de dichas entidades, y que puedan ocasionar perjuicios al consumidor financiero y por último, las demás que establezca de manera previa y general la Superintendencia Financiera de Colombia.

Ese mismo precepto puntualizó que cualquier estipulación o utilización de cláusulas abusivas en un contrato se entendería por no escrita.

En el artículo 12 de esa misma ley, se consagraron distintas prácticas abusivas, como fueron: el condicionamiento al consumidor financiero por parte de la entidad vigilada de que este acceda a la adquisición de uno o más productos o servicios que presta directamente o por medio de otras instituciones vigiladas a través de su red de oficinas, o realice inversiones o similares, para el otorgamiento de otro u otros de sus productos y servicios, y que no son necesarias para su natural prestación; el iniciar o renovar un servicio sin solicitud o autorización expresa del consumidor; la inversión de la carga de la prueba en caso de fraudes en contra de consumidor financiero y las demás que establezca de manera previa y general la Superintendencia Financiera de Colombia. El parágrafo de este precepto, perentoriamente dispuso que las prácticas abusivas estaban prohibidas a partir del inicio de vigencia de la norma y serían sancionables conforme lo dispone la Superintendencia Financiera de Colombia y la ley.

En desarrollo de esta nuevo marco normativo, en el año 2011 la Superintendencia Financiera emitió dos circulares: la circular 038 de 6 de septiembre de 2011, en ejercicio de las facultades legales derivadas del artículo 11.2.1.4.2 del Decreto 2555 de 2010 y de los artículos 7ํy y 9o de la ley 1328 de 2009, adicionó el numeral 9 del título I , del capítulo sexto de la Circular Básica Jurídica relativa a "Información al consumidor financiero" y ordenó a las entidades del sistema financiero poner a disposición de los consumidores información detallada y, por separado, de cada uno de los productos y servicios que presta a través de sus páginas web y en sus oficinas, antes de la celebración del contrato, durante su ejecución e incluso después de la terminación del mismo. De esta manera estableció un marco de información a los 
consumidores financieros, en donde se destacan, respecto de la actividad aseguradora, las obligaciones de suministrar a los consumidores información sobre las coberturas básicas con sus exclusiones, valor de los deducibles, períodos de carencia, trámites que se deben adelantar para obtener el pago del seguro, los plazos y forma de acreditar la ocurrencia del siniestro, entre otras.

Por su parte, en la Circular 039 de 6 de septiembre de 2011 proferida por la Superintendencia, en virtud de las facultades consignadas en los literales e) y d) de los artículos 11 y 12 de la ley 1328 de 2009 y en el numeral 9 del artículo 11.2.1.4.2 del Decreto 2555 de 2010, adicionó el numeral 10 sobre "Cláusulas y prácticas abusivas" del capitulo sexto, del Título I de la circular Básica Jurídica.

Dicha Circular39 reiteró que, de conformidad con lo dispuesto en el parágrafo del artículo 11 de la ley 1328 de 2009, las estipulaciones que contrariaran lo previsto en dicha ley y en la circular en cuestión, se tendrían como no escritas o sin efectos para el consumidor financiero.

Por su parte, la ley 1480 de 2011 o nuevo estatuto del consumidor, en cuanto a la aplicabilidad de sus disposiciones, estableció que lo serían respecto de las relaciones de consumo, como también a la responsabilidad de los productores y proveedores frente al consumidor en todos los sectores de la economía respecto de los cuales no existiera regulación especial, evento en el cual se aplicaría la regulación especial y suplementariamente las normas establecidas en dicha Ley.

Para ese efecto, se consagró expresamente que son disposiciones de orden público, lo que conlleva que cualquier estipulación en contrario se tiene por no escrita, salvo en los casos específicos a los que se refiera la ley. A pesar de lo anterior, también se dejo en claro que ese carácter no le resta validez a los arreglos sobre derechos patrimoniales, producto de cualquier método alternativo de solución de conflictos

39 Esa Circular desarrolla las cláusulas que de acuerdo con la ley se reputan como abusivas y con carácter puramente ilustrativo se contemplan algunos supuestos como aquellas que exoneran, atenúan o limitan la responsabilidad de las entidades vigiladas sin permitir el ejercicio de los derechos del consumidor financiero, así como las que autorizan a las entidades vigiladas para cobrar por servicios no prestados o por prestaciones que no impliquen un servicio adicional. Se consagraron prácticas abusivas adicionales a aquellas ya contempladas en la ley 1328 de 2009, es así como se reputan por tales, redactar contratos con letras ilegibles y difíciles de leer a simple vista, realizar cobros por concepto de gastos de cobranza de manera automática y cobrar al consumidor financiero por servicios y productos sin que exista conocimiento previo, autorización o consentimiento expreso de éste. Igualmente, impuso a los defensores del consumidor financiero que debían revisar los contratos de las entidades vigiladas y remitir a la junta directiva de la respectiva entidad o al órgano que hiciera sus veces, con copia a la Superintendencia, un informe detallado de cláusulas y prácticas abusivas identificadas y el cual debía producirse en un plazo de 4 meses contados desde la fecha de expedición de la circular. 
al cual se acuda como consecuencia de una controversia entre el consumidor y el proveedor y/o productor.

Igualmente, se acoge un principio de favorabilidad en el sentido que sus disposiciones deben interpretarse en la forma más favorable al consumidor y por lo mismo, en caso de duda deberá resolverse en favor del consumidor.

En materia de seguros, los artículos $23^{40}$ y $57^{41}$ se refieren al contrato de manera específica y, particularmente, a las exigencias de información sobre las coberturas, exclusiones y cláusulas de garantía.

40 "ARTÍCULO 23. INFORMACIÓN MÍNIMA Y RESPONSABILIDAD. Los proveedores y productores deberán suministrar a los consumidores información, clara, veraz, suficiente, oportuna, verificable, comprensible, precisa e idónea sobre los productos que ofrezcan y, sin perjuicio de lo señalado para los productos defectuosos, serán responsables de todo daño que sea consecuencia de la inadecuada o insuficiente información. En todos los casos la información mínima debe estar en castellano. "PARÁGRAFO. Salvo aquellas transacciones y productos que estén sujetos a mediciones o calibraciones obligatorias dispuestas por una norma legal o de regulación técnica metrológica, respecto de la suficiencia o cantidad, se consideran admisibles las mermas en relación con el peso o volumen informado en productos que por su naturaleza puedan sufrir dichas variaciones.

"Cuando en los contratos de seguros la compañía aseguradora modifique el valor asegurado contractualmente, de manera unilateral, tendrá que notificar al asegurado y proceder al reajuste de la prima, dentro de los treinta (30) días siguientes".

41 ARTÍCULO 57. ATRIBUCIÓN DE FACULTADES JURISDICCIONALES A LA SUPERINTENDENCIA FINANCIERA DE COLOMBIA. En aplicación del artículo 116 de la Constitución Política, los consumidores financieros de las entidades vigiladas por la Superintendencia Financiera de Colombia podrán a su elección someter a conocimiento de esa autoridad, los asuntos contenciosos que se susciten entre ellos y las entidades vigiladas sobre las materias a que se refiere el presente artículo para que sean fallados en derecho, con carácter definitivo y con las facultades propias de un juez.

En desarrollo de la facultad jurisdiccional atribuida por esta ley, la Superintendencia Financiera de Colombia podrá conocer de las controversias que surjan entre los consumidores financieros y las entidades vigiladas relacionadas exclusivamente con la ejecución y el cumplimiento de las obligaciones contractuales que asuman con ocasión de la actividad financiera, bursátil, aseguradora y cualquier otra relacionada con el manejo, aprovechamiento inversión de los recursos captados del público.

La Superintendencia Financiera de Colombia no podrá conocer de ningún asunto que por virtud de las disposiciones legales vigentes deba ser sometido al proceso de carácter ejecutivo. Tampoco podrán ser sometidas a su competencia acciones de carácter laboral. Los asuntos a los que se refiere el presente artículo se tramitarán por el procedimiento al que se refiere el artículo $\underline{58}$ de la presente ley.

PARÁGRAFO. Con la finalidad de garantizar la imparcialidad y autonomía en el ejercicio de dichas competencias, la Superintendencia Financiera de Colombia ajustará su estructura a efectos de garantizar que el área encargada de asumir las funciones jurisdiccionales asignadas por la presente ley cuente con la debida independencia frente a las demás áreas encargadas del ejercicio de las funciones de supervisión e instrucción. 
En lo relativo a las cláusulas abusivas, en el momento actual, ciertamente se han consolidado unos criterios respecto de las cláusulas vejatorias o abusivas en los contratos de adhesión y para ello baste recordar que a este respecto, la Corte Suprema de Justicia en pronunciamiento de 30 de enero de 2001 aseveró que en las distintas legislaciones que se han producido a nivel universal sobre cláusulas abusivas, incluyendo la disposición del artículo 133 de la ley 142 de 1994, sobre servicios públicos, "...se advierten como características arquetípicas de las cláusulas abusivas -primordialmente-: a) que su negociación no haya sido individual; b) que lesionen los requerimientos emergentes de la buena fe negocial - vale decir, que se quebrante este postulado rector desde una perspectiva objetiva: buena fe, probidad o lealtad -, y c) que genere un desequilibrio significativo de cara a los derechos y las obligaciones que contraen las partes".

En la ley 1480 de 2011, el artículo 43 las definió en los siguientes términos: "Son cláusulas abusivas aquellas que producen un desequilibrio injustificado en perjuicio del consumidor y las que, en las mismas condiciones, afecten el tiempo, modo o lugar en que el consumidor puede ejercer sus derechos. Para establecer la naturaleza y magnitud del desequilibrio, serán relevantes todas las condiciones particulares de la transacción particular que se analiza.

"Los productores y proveedores no podrán incluir cláusulas abusivas en los contratos celebrados con los consumidores, En caso de ser incluidas serán ineficaces de pleno derecho".

Cláusulas abusivas cuya presencia puede presentarse tanto en las relaciones de consumo como en cualquier tipo de relación negocial, pues hoy día se encuentra superada la tesis que tales estipulaciones no se presentan en las relaciones interempresarios, habida cuenta que la tendencia en la doctrina moderna es la de reconocer que en las relaciones contractuales entre empresarios, también pueden presentarse situaciones de desequilibrio por la presencia de signos y evidencias de dependencia de carácter técnico y económico y que imponen que se exija a las partes un deber de colaboración estrecho entre ellas y aún más, a que se traduzca en una verdadera asistencia y orientación hacia el profesional que está en situación de inferioridad y que en últimas, no puede reputársele como un cuerpo extraño que se introduce de manera subrepticia en el contrato, ya que no es otra cosa que una de las tantas proyecciones de la buena fe.

De manera que, tales cláusulas abusivas no son patrimonio exclusivo de las relaciones de consumo; se proscriben porque, en últimas, pretenden colocar a una de las partes a merced de la otra, por lo cual atentan contra el orden público y más específicamente en su proyección de orden público económico ${ }^{42}$, el cual tutela principios como la libertad de empresa y la buena fe, porque como lo asevera el jurisconsulto español Manuel GARCIA-AMIGO:"...la idea de orden público es uno de esos conceptos válvula

42 Farina, Juan M. "Contratos Comerciales Modernos" Editorial Astrea, Buenos Aires 1997, página 161. 
a través de los cuales el ordenamiento jurídico vigente respira las nuevas ideas y se hace posible que aún sin varias las disposiciones legales, las relaciones económicas adopten una normatividad con una diferente inspiración, plegándose a las nuevas realidades sociales mediante una interpretación progresiva..." ${ }^{\prime 3}$ a lo cual añade, Luis DIEZ-PICAZO que: "En realidad, teniendo en cuenta el amplio concepto de principios generales del Derecho (...) el orden público no viene a ser más que la expresión que se le da a la función de aquellos principios en el ámbito de la autonomía privada, consistente en limitar su desenvolvimiento en lo que los vulnera". ${ }^{44}$

En consecuencia, con base en las premisas anteriores, bajo la denominación cláusula abusiva, quedan comprendidas aquellas estipulaciones que puedan tener, como objeto o como consecuencia, un desequilibrio significativo entre los derechos y obligaciones de las partes en el contrato, que puede provenir del abuso en la situación de dependencia económica que pueda tener una de las partes respecto de la otra y que le permite crear una ventaja excesiva desde el momento de concreción del vínculo o en un instante posterior, o que aún puede ser el producto de una situación de hecho que propicia la parte dominante en el contrato, en el curso de ejecución del mismo, con el ánimo de abrogarse una ventaja que resulta excesiva porque rompe la equivalencia de las prestaciones de las partes al privilegiar sus propios intereses y desquicia abiertamente la justicia contractual ${ }^{45}$.

De tal manera que la cláusula abusiva se caracteriza por crear un desequilibrio de consideración en las prestaciones de las partes y, de esa manera, rompe el equilibrio propio de la relación contractual y, por esa razón se faculta al juez, para declararla nula por violación de normas imperativas o de orden público o aún inaplicarla, vedándole de esa forma a la estipulación, su eficacia y su carácter vinculante.

Con estas premisas en mente, procede el análisis de algunas estipulaciones que han recibido el señalamiento de resultar excesivas o desproporcionadas en frente de los asegurados.

43 Garcia, Miguel. "Condiciones generales de los contratos", Editorial Revista de Derecho Privado, Madrid, 1969, páginas 265 y 266.

44 Diez-Picazo, Luis. "Sistema de Derecho Civil ", Tecnos, 6ª Edición, 1988, página 383.

45 En materia de contratos abusivos o leoninos, con relación a las soluciones plasmadas en el Derecho anglosajón, se dice que: "...aparecen dos reglas distintas, aunque cada una de ellas bajo el común denominador de la explotación de un contratante particularmente vulnerable. La primera es la doctrina de la "influencia indebida" que se aplica en aquellos casos en que una de las partes contratantes ha ejercido o se encuentra en situación para ejercer un alto grado de control o de determinación sobre la otra, La segunda doctrina denominada de los "convenios desproporcionados o leoninos", establece que si una de las partes obtiene deliberadamente una ventaja de la pobreza o la ignorancia de la otra parte, en forma desproporcionada con el valor real de los bienes, la parte vulnerable o más débil puede pedir la anulación del contrato" 


\subsection{La abusividad que se endilga a las condiciones del amparo de infidelidad}

Como es bien sabido, el amparo de infidelidad de empleados de la póliza global bancaria cubre, bajo las diferentes versiones, los actos deshonestos o fraudulentos cometidos por los empleados del asegurado, ya sea que éstos actúen solos o en coparticipación con terceros y exige que de esos actos se infiera la intención manifiesta que el asegurado sufra la pérdida, lo que en algunos otros clausulados, se adiciona con la exigencia de obtener un provecho personal de carácter económico.

Se ha entendido que bajo la expresión actos deshonestos fraudulentos quedan comprendidos cualquier tipo de actuación de carácter deliberado, intencional o doloso y que por lo tanto se excluyen de la cobertura los actos negligentes de los empleados del asegurado, como también las pérdidas de carácter operacional o especulativo que se originan en el comportamiento de los mercados financieros; aspecto que es materia de análisis en apartes posteriores.

Las exigencias del amparo de infidelidad, en el sentido que se acredite que el proceder del empleado o empleados fue presidido por la intención manifiesta que el asegurado sufriera la pérdida o de obtener un provecho personal de carácter económico, han sido consideradas por algunos como excesivas como quiera que la intención hace referencia al propósito que anima al empleado para desarrollar o ejecutar el acto deshonesto o fraudulento, elemento que es propio de su fuero interno.

Respecto de la exigencia que el empleado deba obtener un provecho personal de carácter económico, se estima que también resulta bastante severa como quiera que los réditos que el empleado hubiera podido obtener de su actuación suelen permanecer ocultos o suficientemente mimetizados, lo que ha conducido a un sector de la doctrina a considerar que ese presupuesto o condicionante del amparo, impone al asegurado una carga probatoria excesivamente onerosa.

En efecto, en el laudo de Andino Capital Markets vs. Interamericana S.A. Cia de Seguros, el Tribunal expresó: "... la prueba de la obtención efectiva, no solamente de la intención, en cuanto a la ganancia financiera personal ilícita suele ser imposible, y en ello le asiste razón a la convocante, porque muchas veces la ganancia permanece fácilmente oculta el escrutinio de la investigación porque incluso puede no llegarse a realizar efectivamente por circunstancias ajenas al autor. Por lo mismo en este caso, esta sería una razón suficiente por sí misma para restarle validez a este condicionamiento..."

Por su parte, en el laudo de Sociedad Fiduciaria Bermúdez y Valenzuela S.A. en liquidación vs. Aseguradora Colseguros S.A. de 30 de agosto de 2002, si bien se reconoció la dificultad que puede entrañar ese beneficio obtenido por los empleados, se dijo: "Es aceptado por doctrina nacional y extranjera que la prueba de la intención

46 "Laudos arbítrales en materia de seguros", publicación de la Cámara de Comercio de Bogotá y Acoldese, Tomo II, Bogotá, 2004, pagina 479. 
puede aparejar algunas dificultades, pero también lo es que como resultado de una apreciación global de las pruebas aportadas y rituadas en el proceso, puede evidenciarse sin equívoco alguno una conducta del empleado dirigida expresamente a procurar un lucro indebido en beneficio propio o de un tercero. Ese beneficio propio, como lucro indebido, provocado por el detrimento patrimonial del tomador asegurado, bien puede ser difícil de acreditar, pero igual puede ser elemento de la violación sistemática de normas básicas de ejercicio del objeto social del tomador asegurado o de sus reglamentos de operaciones, siempre que existan elementos objetivos que permitan demostrar un lucro en el patrimonio del empleado, como modificaciones de sus condiciones habituales de comportamiento social, sobreviniente adquisición de bienes o también el beneficios de terceros ${ }^{\prime \prime 4}$.

Quienes estiman que no se trata de una cláusula abusiva48, aducen que en frente de las entidades del sector financiero no se presenta una situación de inferioridad en términos económicos y, además, esas entidades están obligados a desarrollar programas de administración o gestión de riesgos por exigencias contenidas en disposiciones de carácter regulatorio, por lo que el contrato de seguro, además teniendo en mente las directrices de los Acuerdos de Basilea, cobra una importancia que pudiera calificarse de residual.

Añaden que no hay un verdadero desequilibrio en las prestaciones entre tomador y asegurador, por cuanto el nivel de la prima refleja el grado de exposición de los riesgos que asume la aseguradora y que, no se trata de una exigencia probatoria injustificada, por cuanto lo que pretende es evitar que las compañías de seguros asuman pérdidas derivadas de operaciones de crédito que resultan propios de las actividades especulativas de las entidades del sector financiero y que, por tanto conllevan una contingencia ganancia o pérdida.

Como es sabido, las versiones que exigen que deba existir una ganancia indebida para el empleado mismo o en beneficio de terceros (animus lucri faciendi), establecen un requisito adicional que ha de ser acreditado por el asegurado para que proceda el pago de la indemnización.

Si bien esa exigencia entraña dificultades probatorias enfrente de casos particulares, es evidente que no existe imposibilidad para acreditar ese beneficio pecuniario indebido obtenido por los empleados del asegurado, aunque la actividad probatoria que debe desarrollarse resulta ardua y exigente.

47 "Laudos arbítrales en materia de seguros", publicación de la Cámara de Comercio de Bogotá y Acoldese, Tomo III, Bogotá, 2004, pagina 21.

48 Restrepo, Laura "El amparo de infidelidad de la póliza de seguro global bancario. Análisis desde la perspectiva de las cláusulas abusivas en Colombia", Revista Iberolatinoamericana de Seguros, No. 38, enero-julio de 2013, Pontificia Universidad Javeriana, CILA, FIDES, páginas 189 y ss. 
En este sentido, resulta elocuente lo expuesto en el laudo arbitral de la Sociedad Fiduciaria Bermúdez y Valenzuela S.A. en liquidación contra Aseguradora Colseguros de 30 agosto de 2002, donde se expresó: "Con todo, como quiera que el apoderado de la convocante le endilga abusividad a la manera contractualmente prevista en la condición pertinente del anexo de prueba del "propósito de obtener un beneficio pecuniario" ( pág.22 del alegato de conclusión), el tribunal entiende que respecto de este asunto debe reiterar que evidentemente el acreditamiento de tal exigencia contractual apareja, en ocasiones, dificultades, pero que también es cierto que, como atrás se señaló, la realidad probatoria analizada en su conjunto, como lo impone el artículo 287 del Código de Procedimiento Civil, puede indicarle al juzgador de derecho privado un cúmulo de circunstancias que, con sujeción a la sana crítica, le evidencien un inequívoco propósito de procurar un indebido beneficio para un tercero. La dificultad de una prueba no conlleva necesariamente a que la cláusula que la exige sea injusta o abusiva"49.

En un pronunciamiento más reciente en el cual el demandante calificó de abusiva la exigencia de beneficio pecuniario por parte de los empleados, se señaló, de una parte, que la cláusula de infidelidad no es ambigüa, pues la estipulación señalaba de manera clara los requisitos que debían satisfacerse para exigir la efectividad del amparo y, en relación con el señalamiento del carácter vejatorio de la misma, se puntualiza que: “...el Tribunal considera que la cláusula de la que se pretende su ineficacia no es abusiva, sino que, por el contrario, se trata de una manifestación del ejercicio legítimo de parte de la aseguradora de su facultad de delimitar los riesgos que está dispuesta a cubrir en virtud del contrato de seguro" y añadió: "Con esta delimitación del riesgo, la aseguradora de modo explícito matizó de manera especial el cubrimiento de aquellas operaciones que se enlistan en el segundo inciso de la cláusula 1.1 KFA 81. Ahora bien, para que el ejercicio de dicha facultad de demarcar el riesgo asegurado desborde sus límites, convirtiéndose en un acto arbitrario, se requiere que se trate de una conducta carente de justificación, principalmente de tipo técnico, actuándose en franca contravía del equilibrio contractual y de los postulados de la buena fe, lo cual no ocurre en este caso $^{\prime \prime 50}$.

\subsection{La supuesta abusividad de la cláusula de limitación de descubrimiento}

Como la póliza ampara las pérdidas descubiertas durante la vigencia de la póliza, lo usual es que la cobertura de la póliza opere de manera retrospectiva, vale decir, la póliza responde por pérdidas descubiertas durante la vigencia de la póliza, que deriven de hechos que ya hubieren tenido lugar al momento de inicio de la vigencia de la póliza, pero que sean desconocidos para tomador y asegurador.

49 "Laudos arbítrales en materia de seguros", publicación de la Cámara de Comercio de Bogotá y Acoldese, Tomo III, Bogotá, 2004, pagina 39.

50 Laudo arbitral de 9 de diciembre de 2014, Asesorías e Inversiones S.A. vs. AIG Seguros Colombia S.A. 
En otras palabras, la protección o cobertura de la póliza se retrotrae hasta la denominada "fecha retroactiva" que suele coincidir con la fecha en la que inicialmente el asegurado adquirió la protección del seguro que está negociando o renovando sucesivamente.

En otros términos, en esta modalidad, la cobertura de seguro opera de manera retrospectiva, por cuanto sus efectos se retrotraen hasta la denominada fecha retroactiva y que suele coincidir con la fecha en que inicialmente el asegurado adquirió la protección del seguro; de manera que bajo esta hipótesis, la cobertura se extendería a las pérdidas ocurridas con posterioridad a dicha fecha retroactiva y descubiertas durante la vigencia que se encuentre en curso; en otros términos, la cobertura se extendería a las pérdidas ocurridas con posterioridad a dicha fecha retroactiva y descubiertas o reclamadas durante la vigencia que se encuentre en curso.

Con el mismo propósito, existe otra modalidad de amparo distinta a la de "fecha retroactiva" y que también funciona de manera retrospectiva, que se presenta cuando la cobertura por descubrimiento se supedita a la llamada "cláusula de limitación de descubrimiento" (conocida en inglés como "discovery limitation clause"), que puede encontrarse incorporada como anexo de la póliza (que es la práctica más reciente) o corresponder a una exclusión (así ocurría hace más de una década).

En virtud de esta estipulación denominad de "limitación del descubrimiento", se suprime la "fecha retroactiva" o, si se quiere, se otorga amparo de manera retrospectiva y en forma ilimitada.

Claro está, que, cuando la cobertura se otorga de manera retrospectiva, se da por descontado el desconocimiento absoluto por parte del tomador del amparo de hechos o circunstancias que hubieran dado, o puedan dar lugar a reclamo, en virtud del postulado de la buena fe y del deber de declaración sobre las circunstancias constitutivas del estado del riesgo y de las afectaciones que hubiera experimentado previamente.

Por esa razón, la cláusula de limitación de descubrimiento expresa que no habrá obligación de parte de la aseguradora con respecto a ningún reclamo que provenga de cualquier circunstancia u ocurrencia que hubiere sido notificada bajo cualquier otra póliza de seguros que hubiera estado vigente con anterioridad al inicio de la póliza, o cuando se derive de cualquier circunstancia u ocurrencia conocida por el asegurado antes de la iniciación del amparo y que hubiera omitido poner en conocimiento de la compañía a la iniciación del mismo.

Algunos han considerado que la cláusula de limitación de descubrimiento, es una forma velada de ocultar la alegación de una eventual reticencia y disfrazarla de exclusión y por esas razones la califican de abusiva; sin embargo, olvidan que esa modalidad de amparo está acorde con el hecho que el riesgo es un hecho futuro e incierto y por lo mismo, los hechos ciertos como no constituyen riesgo "... son extraños al contrato de seguro" (art. 1054, ibídem). 
Argumento que ha generado desconcierto entre los reaseguradores del mercado internacional, porque las cláusulas de limitación de descubrimiento son muy comunes en el mercado de Londres bajo las pólizas de responsabilidad civil, como una alternativa a las fechas retroactivas. Se estima que son convenientes para ambas partes, en aquellos casos donde el asegurado busca unas capas adicionales de cobertura y las nuevas capas impondrían fechas retroactivas distintas respecto de aquellas aplicables a las capas de cobertura existentes.

De tal manera que la "cláusula de limitación de descubrimiento" constituye una ventaja muy importante para el asegurado, ya que el eventual conocimiento que hubiere tenido de los hechos o circunstancias que dieron lugar al reclamo, no daría lugar a la invalidez o nulidad del contrato en su totalidad por "reticencia" o "inexactitud", sino que le restaría efectividad al amparo respecto del reclamo en cuestión, habida cuenta que operaría una "exclusión" o "ausencia de cobertura" de ese siniestro particular, y no un problema de nulidad o invalidez del contrato de seguro.

En esa hipótesis, el contrato de seguro continuaría surtiendo efectos y, por tanto, continuaría amparando riesgos que pudieran dar lugar a otros siniestros y que se derivaran de hechos ocurridos con anterioridad a la vigencia de la póliza, siempre y cuando los hechos o circunstancias fueran absolutamente desconocidos para el tomador $y$ asegurador ${ }^{51}$, lo que está acorde con el hecho que el riesgo es un hecho futuro e incierto y, por lo mismo, los hechos ciertos, al no constituir riesgos, son ajenos al contrato de seguro

De otro lado, ese argumento de abusividad con que se tacha la cláusula de limitación del descubrimiento, pasa por alto el marco normativo propio de las modalidades de descubrimiento y claims made.

En consecuencia, no se aprecia desequilibrio excesivo o injustificado alguno que ocasione dicha estipulación, por cuanto lo que pretende es que los hechos o circunstancias conocidas por el tomador le sean puestas de presente al segurador, como reflejo de la obligación de lealtad que ha de preservarse entre las partes. Es evidente, que es legítimo esperar que el tomador del amparo no guarde silencio sobre circunstancias que, de haber sido conocidas por el asegurador, lo hubieran conducido a abstenerse de contratar o a hacerlo en términos económicos y de cobertura diferentes.

Como corolario del principio de la buena fe, sobre las partes pesa una obligación de lealtad en todas las etapas del iter contractual y en la fase precontractual, este se

51 La cláusula de limitación de descubrimiento expresa que no habrá obligación de parte de la aseguradora con respecto a ningún reclamo que provenga de cualquier circunstancia u ocurrencia que hubiere sido notificada bajo cualquier otra póliza de seguros que hubiera estado vigente con anterioridad al inicio de la póliza; o cuando se derive de cualquier circunstancia u ocurrencia conocida por el asegurado antes de la iniciación del amparo y que hubiera omitido poner en conocimiento de la compañía a la iniciación del amparo. 
traduce en que cada uno de los extremos de esa relación orientada a la consolidación y formación del vínculo negocial, deban facilitarse todas las informaciones que, según la naturaleza del contrato, no sólo sean necesarias, sino también de su conocimiento.

De manera que esta observación deja entrever es una dificultad de comprensión de un aspecto que, técnicamente, corresponde a una práctica generalizada propia del manejo de este tipo de coberturas.

A este respecto, en un pronunciamiento arbitral reciente se expresa lo siguiente: "...la lectura de la previsión contractual que aquí se analiza conduce al Tribunal a concluir que la misma corresponde, legítimamente, a una exclusión, y no encuentra que ella encubra, disfrace o prepare un subterfugio para eludir el compromiso de pagar la correspondiente indemnización y alegar a discreción una reticencia. El Tribunal encuentra una condición que no es ilícita, estipulada en desarrollo de la facultad de delimitación contractual del riesgo, y entiende que el debate acerca de si un riesgo se encuentra amparado o no, y de si la mencionada exclusión permite o no aceptar una reclamación, corresponde a una discusión respecto del cumplimiento del deber de información aludido, toda vez que la eventual discusión sobre una reticencia o inexactitud no giraría en torno a la legalidad de esta cláusula"52.

\subsection{Amparo de infidelidad y pérdidas operacionales}

Otra nota distintiva del amparo de infidelidad de empleados es que no abarca pérdidas operacionales del asegurado.

En algunas pólizas, se encuentran aclaraciones en los clausulados, según las cuales, se da por sentado que las negociaciones con valores o divisas o las diversas modalidades de concesión de créditos solo gozan de la cobertura si provienen de actos deshonestos de empleados del asegurado, ejecutados con la finalidad manifiesta de lucrarse y siempre que el beneficio pecuniario no consista en salarios, comisiones, honorarios, promociones o cualquier tipo de emolumento de naturaleza similar ${ }^{53}$.

Esta última aclaración aparece en la mayoría de las pólizas globales bancarias dentro del cuerpo del amparo de infidelidad o en el anexo de exclusión de pérdidas operacionales o trading loss exclusión rider como se conoce en el mercado de Londres $^{54}$.

52 Laudo de 12 de noviembre de 2014 de Banco de la República contra Seguros Generales Suramericana S.A. y Allianz Seguros S.A. (Arbitros: José Armando Bonivento, Jorge Pinzón Sánchez y José Vicente Guzmán), página 216.

53 Narvaez, Jorge Eduardo "Pérdidas operacionales y amparos de infidelidad bajo las pólizas globales bancarias", Revista Iberolatinoamericana de Seguros, No. 33, enero-junio de 2012, publicación de Aida- Cila y de la Pontificia Universidad Javeriana, páginas 149 y ss.

54 En algunas pólizas se contempla una exclusión sobre pérdidas operacionales como ocurre con la exclusión J de la DHP 84, sin embargo, resultan útiles estas apreciaciones: "The financial institution bond does not cover loss resulting directly or indirectly from trading with or without the knowledge of the insured, except when covered under the forgery or 
De manera que, sólo se trataría de pérdidas que afectan el amparo de infidelidad de empleados, aunque revistieran, prima facie, el carácter de operacionales, si eran desconocidas para la entidad financiera, a pesar de haber actuado de manera diligente y de contar con mecanismos de verificación idóneos, pues, aunque el funcionario o los funcionarios excediera los límites de negociación autorizados, el respectivo empleado oculta esa circunstancia a través de la alteración de registros internos del banco, o en virtud de la introducción de transacciones falsas o ficticias en los programas de sistemas que registran y conservan los datos relativos a las mismas, todo ello con el propósito de ocultarlas y de evadir los controles de la entidad encaminados a monitorearlas, vale decir, logra su cometido a través de la manipulación de los sistemas de la misma entidad.

Esta exclusión se presenta usualmente en los siguientes términos: “j) Por pérdidas que resulten directa o indirectamente de negocios "trading" con o sin conocimiento por parte del asegurado, en nombre del asegurado o de cualquier otra forma, ya sea que esté representada o no por una deuda o saldo que muestre qué debe el asegurado sobre cualquier cuenta a un cliente real o ficticio, y no obstante cualquier acto u omisión por parte de cualquier empleado en relación con cualquier cuenta relacionado con tal negocio, endeudamiento o saldo"

Lo que persigue esta exclusión es colocar por fuera de la cobertura las pérdidas meramente operacionales, es decir, aquellas provenientes de un error de juicio y en las cuales no ha existido el propósito del empleado de inferir daño al asegurado.

En consecuencia, para que un detrimento económico que ha sufrido la entidad asegurada como consecuencia de actos deshonestos o fraudulentos de sus empleados, no sea catalogada como una pérdida operacional o de carácter puramente comercial, debe acreditarse que el empleado actúo de manera fraudulenta y que pretendió irrogarle una pérdida al banco y, en frente de ciertos clausulados que resultan más exigentes, acreditar también que el empleado o empleados persiguieron una ventaja económica para ellos o para un tercero ${ }^{55}$.

alteration, or securities insuring agreements of the bond". (Armstrong, Edgar y Stevens, Mark "Digest of Bank Insurance", sixth edition, Insurance and Protection Division, American Bankers Association, Washington, 1.977, pág. 11)

55 En sentencia de 4 de febrero de 2010 proferida por la Sección Primera del Consejo de Estado, se condenó a pagar a una aseguradora la suma contemplada en la condena de un fallo de responsabilidad fiscal. La Corporación consideró que la póliza global bancaria había sido afectada, habida cuenta que la exclusión de operaciones de crédito no operaba; el detrimento patrimonial del banco había sido determinado en la solicitud de crédito como en la posterior aprobación del mismo, había sido tramitado de manera irregular por los funcionarios encargados de diligenciarlo, quienes eran conocedores tanto de los manuales de procedimientos internos de la entidad bancaria como de las garantías exigidas para hacer desembolsos de créditos, lo que condujo a que en el trámite de su aprobación los empleados incurrieron en conductas culposas que generaron un grave perjuicio para la entidad. 
A propósito de lo expuesto en el párrafo anterior, resulta claramente desventajosa una cláusula KFA 81 respecto de un clausulado de infidelidad DHP-84 con exclusión "j". Así mismo, es evidente que resulta aún más benéfico un clausulado DHP73 con exclusión J, frente a una versión KFA81 o a un amparo basado en la DHP84 con exclusión J, si bien sería deseable que dicha exclusión, para logra un grado adecuado de certeza contractual, se complementara con la salvedad que una pérdida no será considerada como operacional en frente de los amparos de infidelidad de empleados y de falsificación.

En conclusión, no es cierto, como lo aseveran algunos de forma ingeniosa, pero claramente con ligereza y de forma errónea, que bajo los distintas cláusulas de infidelidad se presentan diferencias más de forma que de fondo, pues quienes así opinan olvidan que bajo la cláusula de infidelidad de la DHP- 84, la pérdida resultante para el asegurado de actos fraudulentos o deshonestos de sus empleados, ya sean cometidos por éstos solos o en complicidad con terceros, requiere que se acredite que la intención de tal empleado fue la de causarle dicha pérdida, lo cual se demuestra con la pérdida misma. Igualmente, olvidan que la exclusión J de la versión DHP 84 excluye las operaciones comerciales, las cuales ciertamente no se encuentran definidas, pero es claro que son aquellas resultantes de las operaciones normales de una entidad financiera, o si se quiere, aquellas que están comprendidas en el giro ordinario de sus negocios; lo que acontece es que una pérdida deja de ser comercial u operacional y se erige en una de infidelidad, cuando las operaciones en cuestión son desarrolladas con el propósito de defraudar a la respectiva entidad y para que opere la cobertura tan sólo se requeriría la demostración de la pérdida para la respectiva entidad asegurada ${ }^{56}$.

A juicio del Consejo de Estado, la falta de pago del crédito encuadraba dentro del amparo de infidelidad de empleados, aunque éste exige la comisión de conductas intencionales y dolosas, pues los funcionarios de la entidad bancaria habían sido declarados fiscalmente responsables, por razón de la autorización y desembolso del préstamo, sin el lleno de los requisitos legales; conducta que, en criterio de ese Tribunal, había sido deshonesta y fraudulenta por parte de los funcionarios, pues tenían conocimiento de antemano de tales requisitos.

56 Es cierto que la misma finalidad cumple la versión KFA 81, pero a través de una forma mucho más gravosa para el asegurado, como quiera que respecto de las pérdidas operacionales "esta póliza cubre única y directamente los actos deshonestos o fraudulentos por parte de empleados del asegurado cometidos con la intención manifiesta de hacerlo y el cual resulte en un provecho indebido para ellos mismos distinto de salarios, honorarios, comisiones, promociones y otros emolumentos similares". En otras palabras, además de la demostración de la pérdida sufrida por la entidad asegurada, debe acreditarse el provecho indebido obtenido por los empleados. Evidencia clara de esta aseveración, se encuentra en el Laudo arbitral de 9 de diciembre de 2014, Asesorías e Inversiones S.A. vs. AIG Seguros Colombia S.A. y en el Laudo de 24 de octubre de 2012 de Proyectar Valores vs. Chubb de Colombia. Además de las consideraciones anteriores, las dificultades de carácter probatorio que en la praxis entraña el clausulado de infidelidad de la KFA 81, la hacen más restrictiva lo que se refleja en el precio de la misma, vale decir, suele ser inferior al que se establece para el amparo de infidelidad de la versión DHP-84 con exclusión "j", lo cual obedece a que ese menor precio es consecuente con la menor protección de la KFA 81. 


\subsection{El deber de mitigación del daño}

Este aspecto ha cobrado importancia en el último quinquenio; se hace particular hincapié en el deber del asegurado de mitigar su daño, por ser los asegurados entidades de carácter profesional que deben establecer y ejecutar exigentes programas de gestión de riesgos y como respuesta al imperativo de aplicar la doctrina anglosajona de "consecuencias evitables" (doctrine of avoidable consequences) que ha tenido acogida bajo el denominado deber de mitigación del daño; se pretende evaluar si, como consecuencia del siniestro, la obligación fue debidamente satisfecha por el asegurado, para lo cual propugna por la aplicación de un test de razonabilidad, vale decir, determinar las medidas que ha debido aplicar un asegurado razonable para disminuir el importe de los eventuales daños.

De otra parte, resulta relevante este deber de mitigación, porque es frecuente encontrar en algunas pólizas, una exclusión que se expresa de la siguiente manera: "pérdidas o daños causados por actos fraudulentos cometidos por un trabajador o con su concurso, a partir del momento en el cual el asegurado tenga conocimiento de la comisión de un acto de tal naturaleza, contra el mismo asegurado o contra un tercero y sin perjuicio de obtener la indemnización respectiva por pérdidas o daños de valores que se encuentren en tránsito bajo la custodia de dicho trabajador en ese momento", la cual tiene la virtud de colocar por fuera de la protección las defraudaciones que ocurran con posterioridad a la fecha de descubrimiento por parte del asegurado, pero por supuesto, no afecta aquellos hechos ocurridos con anterioridad a esa fecha, aunque esas pérdidas o circunstancias aún no hubieran sido conocidas por el asegurado.

Pues bien, el estatuto mercantil colombiano, impone al asegurado en el artículo 1074, la obligación de evitar la extensión y propagación del siniestro, de tal suerte que debe proceder de manera diligente y profesional desde el momento mismo en que descubre las circunstancias que podrían dar lugar a un siniestro; habrá de adelantar las investigaciones encaminadas a establecer los responsables del siniestro y la forma de operación de éstos, habida cuenta que es palmario dilucidar esas circunstancias para adoptar las medidas que puedan ser idóneas y apropiadas para pretender neutralizar y conjurar la extensión del eventual siniestro y, claro está, la disposición no supedita el reembolso de esos gastos a la obtención de un resultado fructífero para evitar o minimizar el siniestro; es evidente que el criterio de utilidad fue desechado en ese precepto legal y, en su lugar, se adoptó el criterio de razonabilidad, prudencia y diligencia en el cumplimiento de la obligación de precaver la ocurrencia del riesgo o de aminorar sus consecuencias dañinas.

En este sentido, desde un ángulo estrictamente jurídico, es claro que la obligación de evitar la extensión y propagación del siniestro es una obligación de medios y no de resultado, por cuanto al tenor del reconocido aforismo de antaño "nadie está obligado a lo imposible" ("ad impossibilitum nulla obligatio est"). 
Aún más, resultaría sorprendente que el asegurador adujera que el asegurado incumplió sus obligaciones, cuando a pesar de la existencia de deberes de colaboración y cooperación que dimanan de toda relación contractual, el asegurador no formule sugerencias o instrucciones en su momento, como tampoco exprese reparos respecto de las medidas adoptadas por el asegurado para proteger su patrimonio.

A este respecto, con particular tino, el desaparecido maestro Efrén OSSA puntualiza: "Todas las medidas que la prudencia aconseje encaminadas a controlar la proyección del siniestro sobre los intereses asegurados, a atemperar, en otros términos, la magnitud del daño patrimonial, no importa la medida en que haya de ser compartido por el asegurador, integran el contenido de estas cargas. Neutralizar, por uno u otro medio, la causa, hacer lo conducente para aislar sus efectos, destruir, si fuere necesario, algunos bienes para prevenir peores pérdidas, todo esto cabe dentro del objetivo final de la ley. A la cual importan los medios, con tal que sean oportunos y razonables, mas no los resultados" ${ }^{\prime 57}$. (Se destaca)

\section{LAS COBERTURAS COMPLEMENTARIAS AL AMPARO DE LA GLOBAL BANCARIA}

Las entidades financieras como complemento de la póliza global bancaria, para lograr una protección que resulte tanto integral como eficiente, suelen contratar el anexo de responsabilidad profesional bancaria, el seguro de directores y administradores, y el seguro de fraude por sistemas computarizados.

\section{El cometido de tales coberturas}

El amparo de responsabilidad civil profesional bancaria opera sobre la base de reclamaciones presentadas durante la vigencia o claims made, y provee indemnización al asegurado con respecto a la responsabilidad en que incurra ante terceros en la realización de operaciones bancarias, por reclamos en materia de resarcimiento o compensación de daños, incluyendo los honorarios y gastos en que hubiera incurrido el reclamante.

Por su parte, el seguro de fraude por sistemas computarizados otorga amparo respecto de actos dolosos de terceros cometidos contra el asegurado que resulten en transferencia, pago o entrega de dineros o de bienes, los cuales pueden obedecer a pagos realizados de la cuenta de un cliente por manipulación del sistema de cómputo del asegurado; por el ingreso fraudulento de datos o de instrucciones; o por destrucción de datos; o por la introducción de virus; o por haber confiado en comunicaciones electrónicas autorizando pagos o transferencias o la entrega de bienes, o dirigidas a un depósito centralizado de valores autorizando la compra, venta o

57 Ossa, Efrén. "Teoría General del seguro- El contrato-", Segunda edición, Editorial Temis Ltda, Bogotá, 1991, páginas 413 y 414. 
pignoración de un título; o por razón de un tele-facsímil o por instrucciones verbales o telefónicas que aparezcan fraudulentamente realizadas por una persona autorizada.

De otro lado, el seguro de directores y administradores (D\&O) tiene por objeto amparar a los directores y administradores señalados en la respectiva póliza (que generalmente coinciden con los que la ley reputa como tales), con respecto a las reclamaciones que sean formuladas directamente contra de ellos durante la vigencia de la póliza y ocurridas con posterioridad a la fecha retroactiva. Reclamaciones en las cuales se les imputa responsabilidad en el desempeño de sus cargos en la respectiva entidad, por las faltas de gestión o incumplimiento de sus deberes respecto de terceros, de la sociedad o de sus socios.

\section{La cobertura de responsabilidad civil profesional}

Es una cobertura que tiene carácter adicional o suplementario y lo cual explica porqué se encuentra, usualmente, como un anexo de la BBB

\subsection{El propósito de esta cobertura}

Las distintas versiones de pólizas que han existido en el mercado, son clausulados de carácter estándar a nivel universal, diseñadas para bancos comerciales, que amparan las actividades propias de su objeto social, pero claro está, que correspondan a "servicios bancarios" ${ }^{15}$ y claro está, la finalidad que pretende cumplir el amparo en cuestión, se encuentra expresada en la denominada cláusula operativa de la póliza, en las cláusulas de exclusiones y en los anexos, habida cuenta que doctrinal y jurisprudencialmente, se ha expresado, reiteradamente, que las pólizas de seguros son de interpretación restrictiva y se limita a los términos expresados en la "escritura contentiva" del contrato.

No sólo corresponde a un formato estándar, sino que también se ha caracterizado por su carácter rígido y prácticamente inmodificable, habida cuenta que no posee anexos o extensiones de cobertura que permitan ampliar su protección. Esa práctica también se extiende a los formularios de solicitud o declaraciones de asegurabilidad, que tienen el mismo carácter de ser estandarizados.

Evidentemente, tales clausulados no tienen la virtud de cubrir todos los riesgos que pueden gravitar en las actividades de un banco comercial, por lo que son, claramente, un componente en el programa de seguros y en la estrategia de administración o gestión de riesgos.

El cometido de la cobertura de responsabilidad profesional no es otro que proteger a la entidad bancaria o financiera contra reclamaciones formuladas por

58 En el mercado americano se hace referencia a listed "professional activities" $\mathrm{y}$ "professional services for a client or a customer" ("Digest of Bank Insurance", American Bankers Association, sixth Edition, 1991, páginas 238 y 239. 
sus clientes como consecuencia directa de actos negligentes, errores y omisiones negligentes de sus empleados en el desarrollo de las labores propias de su actividad financiera, es decir, en la prestación de los servicios de intermediación financiera y, particularmente, como proveedor de servicios bancarios ${ }^{59}$. Ciertamente, los clausulados que se utilizan para las pólizas de responsabilidad profesional bancaria, exigen que las reclamaciones provengan de la prestación de servicios bancarios, como se evidencia con las cláusulas operativas de las versiones ALS 1988 y NMA 3000.

Claramente, esas actividades amparadas son actividades de financiamiento, de intermediación en los pagos y de servicios de inversión financiera, a través de productos que van a tono con los mayores desarrollos tecnológicos y de comunicaciones, con miras a alcanzar un mayor grado tanto de satisfacción como de utilización de esos servicios profesionales por parte de su clientela, y a cambio de un estipendio o remuneración ${ }^{60}$.

59 En el formulario de solicitud se indaga sobre los servicios bancarios, para que el asegurador pueda evaluar su exposición; preguntas que guardan correspondencia con la finalidad del amparo y lo cual determina el contexto bajo el cual deben ser entendidas las estipulaciones de esta póliza. Como el formulario es parte integrante de la póliza ( art. 1048, C. de Co.), por ello se asevera categóricamente que la póliza de responsabilidad profesional bancaria exige que las reclamaciones provengan de la prestación de servicios bancarios, como se expresa tanto en la cláusula operativa de la póliza como en el formulario de solicitud. Formulario que persigue la obtención de detalles sobre la naturaleza, características y aleatoriedad de las actividades que serán materia de cobertura, lo que explica que contemple una sección destinada de manera exclusiva a los servicios de intermediación financiera del proponente, habida cuenta que este aspecto es determinante y crucial para alinderar la extensión real y el contenido de la cobertura; no otra es la razón por la cual se indaga sobre: porcentaje aproximado de los ingresos totales del proponente que se derivaron de préstamos comerciales domésticos y externos; préstamos interbancarios domésticos y externos; leasing o arrendamientos financieros; financiación de negocios; operaciones barter o swap; negociaciones de divisas; negociaciones en mercados de commodities; negociaciones en valores; asesoría en fusiones y adquisiciones; colocación de acciones y nuevas emisiones; administración de fondos; capital a riesgo o venture capital; asesorías en el exterior.

Como el formulario de solicitud es parte integrante de la póliza, es evidente que esta cobertura de responsabilidad profesional bancaria exige que las reclamaciones provengan de la prestación de servicios bancarios como se expresa en el formulario de solicitud, lo cual implica el desarrollo de una actividad en la cual la respectiva entidad recibe algún tipo de estipendio o remuneración, y que corresponde a cualquiera de los tipos de operaciones activas, pasivas o neutras, a las cuales se hizo mención anteriormente.

60 Servicios que, si bien, no son materia de definición en la póliza, atendiendo al contexto propio del amparo, es evidente que a esa expresión le resulta aplicable la definición contenida en la ley colombiana (art. 822, C. de Co.), vale decir, el artículo 6oㅡ, numeral

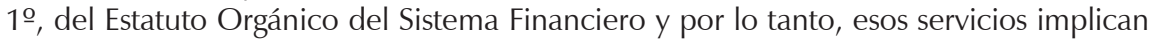
el desarrollo de una actividad en la cual la respectiva entidad recibe algún tipo de estipendio o remuneración y que corresponde a cualquiera de los tipos de operaciones activas, pasivas o neutras propias de la banca comercial. 
En lo que toca con la naturaleza del amparo otorgado bajo el seguro de indemnización profesional, algunos consideran que el alcance de esta cobertura se entiende referido al desarrollo de las actividades que constituyen el objeto social de la misma; sin embargo, esta aseveración es inexacta, por cuanto si ello fuera así, permitiría concluir que los riesgos empresariales, tales como: los riesgos técnicos, y económicos (de rentabilidad de inversiones, nuevos procesos, nuevas estrategias); mercadotécnicos (nueva competencia, lanzamiento de nuevos productos, encarecimiento de productos); socieconómicos (cambios de moda, sociales, problemas de entorno); financieros y bancarios (créditos, dificultades de cobro, dificultades de pago), públicos o legislativos (nacionalizaciones, cambios en el entorno regulatorio, modificaciones en estructuras de negociación o conformación de portafolios) ${ }^{61}$, serían materia de amparo bajo el seguro de responsabilidad profesional.

En síntesis, el espectro de actividades materia de amparo, se encamina a proveer indemnización por los perjuicios que ocasione el asegurado como consecuencia de aquellas actividades que correspondan a servicios de naturaleza bancaria. A esto obedece que la tarifación o el cálculo de la prima o precio del seguro bajo el amparo de responsabilidad profesional, toma como base: el límite de protección; el deducible solicitado; el nivel de exposición al riesgo que resulte de las respuestas al formulario de solicitud; y atendiendo a que sólo se asegura la responsabilidad derivada de las operaciones propias de un banco comercial.

A propósito de un reciente laudo arbitral62, es un hecho que el mercado de reaseguro internacional no tiene, ni ha tenido, disponibilidad para proveer coberturas de responsabilidad profesional de instituciones financieras, para riesgos derivados de las funciones regulatorias de un Banco Central63 como autoridad monetaria, cambiaria y

61 Clasificación de riesgos empresariales de Rodriguez, Eduardo "Administración del Riesgo", Editorial Alfaomega Colombiana S.A., Bogotá, 2002, página 43.

62 Laudo de 12 de noviembre de 2014 de Banco de la República contra Seguros Generales Suramericana S.A. y Allianz Seguros S.A.

63 La falta de capacidad de reaseguro incide en la asegurabilidad de los riesgos cuando las aseguradoras carecen de la capacidad patrimonial suficiente para asumir ciertos riesgos. El riesgo regulatorio, entendido como aquel asociado con las modificaciones en el marco legal o reglamentario que pueda afectar una determinada actividad o ciertas operaciones, conducen a que su asegurabilidad sea bastante limitada, pues, tan sólo en el seguro de crédito a la exportación se amparan eventualidades asociadas con actuaciones soberanas de un Estado, vale decir, determinaciones de gobiernos extranjeros que puedan afectar a los exportadores en determinados sectores de la economía, y en relación con ciertas transacciones. Eventualidades que consisten principalmente en: inconvertibilidad de divisas; alteración significativa de la paridad monetaria que genere situaciones de insolvencia generalizada y expropiación, nacionalización, confiscación o incautación ordenadas por gobiernos extranjeros.

Esa modalidad de cobertura, bajo el seguro de crédito a la exportación se le denomina de riesgos políticos (aunque esa expresión es más amplia porque comprende: guerra civil o internacional, huelgas, conmoción civil, revoluciones, rebeliones, actos de movimientos 
crediticia, como quiera que resulta manifiesto que la exposición derivada de servicios que están por fuera del ámbito de los propiamente bancarios, debe ser asumida por el propio Estado y, particularmente, cuando el banco Central actúa como agente del Gobierno o en virtud del ejercicio de funciones constitucionales, y como quiera que esas decisiones no son de gestión de servicios bancarios ${ }^{64}$ sino que son claramente decisiones de política económica que provienen de ser autoridad monetaria, cambiaria y crediticia, por lo que no pueden encuadrarse como un servicio bancario y, por ende, no corresponden tampoco al ámbito propio de la responsabilidad profesional.

En conclusión, la responsabilidad cubierta por la póliza es efectivamente, aquella que pueda derivarse de la prestación de servicios bancarios por parte de bancos comerciales, como se expresa en el formulario de solicitud, lo que implica el desarrollo de una actividad en la cual la respectiva entidad recibe algún tipo de estipendio o remuneración y que corresponde a cualquiera de los tipos de operaciones activas, pasivas o neutras. Vale decir, puede tratarse de cualquiera de las múltiples actividades de financiamiento, intermediación en los pagos y servicios de inversión financiera, a través de productos que los mismos bancos comerciales actualizan en la misma medida en que se logran mayores desarrollos tecnológicos y de comunicaciones.

subversivos, terrorismo, etc., en realidad se trata estrictamente de riesgos regulatorios), se otorga siempre con la garantía del Estado.

En verdad, los riesgos regulatorios derivados de la actividad de un banco central son inasegurables, ya que equivaldría a trasladar a los aseguradores riesgos derivados de la adopción de decisiones de política económica, que constituyen expresión de la soberanía de un Estado y que, por su naturaleza, son de carácter imponderable e impredecible, lo que hace que estadística y actuarialmente resulte prácticamente imposible cuantificar su probabilidad y, consecuencialmente, la tarifa o precio que habría de corresponderles para ser materia de un contrato de seguro.

64 En el Laudo de 12 de noviembre de 2014 de Banco de la República contra Seguros Generales Suramericana S.A. y Allianz Seguros S.A.se lee lo siguiente: " .. ante la ausencia de una definición legal de "servicios bancarios" en el contexto legal aplicable a la actividad bancaria y financiera en general, existente antes y después de la promulgación de la Constitución de 1991, el uso convencional de la misma no puede ser entendido como una equiparación funcional con la actividad propia de los establecimientos bancarios, que son las entidades que captan en forma masiva y habitual recursos del público para prestarlos y que, además, desarrollan una serie de actividades conexas o complementarias con esa operación de intermediación, que es la que los caracteriza". (...) "En ese orden de ideas, la consideración de una expresión no definida en las leyes, como es la de "servicios "bancarios" -o "financieros"-, a la luz de la normatividad vigente para efectos de su comprensión debe ser usada en el contexto propio de la interpretación e integración de la póliza de la cual forma parte, actividad hermenéutica que, por supuesto, descansa en las leyes; pero que debe partir de la base de lo expresado por los contratantes, en contenido volitivo cuyo entendimiento ha de establecerse de conformidad con los parámetros de interpretación señalados en los citados artículos 1618 y siguientes del Código Civil" (Páginas 182 y 183). 


\subsection{El clausulado más reciente de responsabilidad profesional bancaria}

El desarrollo más reciente respecto de este tipo de coberturas lo constituye el clausulado denominado "Lloyd's NMA 3000" que se hizo público a finales de 2003.

En esta nueva versión se ratifica que el propósito de la cobertura es amparar las pérdidas que se deriven de actos negligentes, errores negligentes $u$ omisiones negligentes por parte de un empleado del asegurado, sin embargo, le fueron adicionadas a la cláusula operativa del amparo, algunos otros supuestos como son incumplimiento negligente de un deber de carácter fiduciario o de carácter profesional; pérdidas derivadas de actos deshonestos o fraudulentos u omisiones por parte de un empleado del asegurado y cualquier tipo de responsabilidad civil, con lo cual se hace énfasis en circunstancias que en su mayor parte ya eran materia de cobertura bajo los clausulados anteriores y razón por la cual algunos conocedores del tema no han dudado en tildar estas modificaciones como de carácter puramente "cosmético".

Respecto de de los actos u omisiones deshonestos o fraudulentos por parte de los empleados del asegurado, la póliza trae una definición en el sentido que se considera por tales, cualquier acto u omisión de un empleado cometido con la intención manifiesta de obtener y que resulte en una ganancia personal financiera para ese empleado, diferente a salarios, honorarios, comisiones, bonos, promociones y cualquier otro tipo de emolumentos similares. De esta manera se estaría otorgando cobertura tanto a los actos, las omisiones de carácter deshonesto fraudulento de los empleados del asegurado pero supeditado de todas maneras a la comprobación que en virtud de esa conducta o esa omisión ha obtenido un beneficio pecuniario y claro está, la presencia de ese requisito despierta dudas con respecto a la efectividad del amparo y, particularmente, en aquellas circunstancias en que los empleados incurren en omisiones de manera deliberada que ocasionan pérdidas a los clientes del banco y de manera refleja a la misma entidad bancaria, porque la praxis ha mostrado que en este tipo de circunstancias, los empleados desatienden las instrucciones de los clientes con el ánimo de cumplir metas comerciales que les son impuestas y donde claramente no existe una apropiación de dineros por parte de tales funcionarios.

En lo relativo la inclusión de la responsabilidad civil, esto tiene incidencia particularmente en el Reino Unido, como se colige de la definición del amparo contenida en la póliza, como quiera que se hace referencia a responsabilidad reclamable bajo la ley inglesa como "tort" y a la violación de disposiciones contenidas en el "Financial Services and Market Acts 2000", pero no tiene trascendencia para el mercado colombiano, por cuanto se encontraba claro que la cobertura de la póliza se encaminaba a amparar pérdidas ocasionadas por negligencia de los empleados en la ejecución de contratos propios de la actividad financiera con sus clientes, como también la eventual responsabilidad de carácter extracontractual que pudiera derivarse respecto de terceros ante circunstancias específicas ( emisión de carta de recomendación; quiebras fraudulentas; reclamaciones por beneficiarios de cheques por su pago indebido; rompimiento injustificado e intempestivo de negociaciones en operaciones de crédito, etc.). 
En materia de exclusiones, esta nueva versión añade algunas otras a las que estaban previstas en el clausulado NMA 2273, como son: pérdidas derivadas de cualquier acto, error u omisión ocurrido con posterioridad al conocimiento por parte del equipo de administración del asegurado (assured's management), el cual se define en la póliza, de cualquier acto u omisión deshonesto fraudulenta de un empleado; reclamaciones de entidades gubernamentales; reclamaciones de carácter laboral; pérdidas derivadas de operaciones con acciones; circunstancias de lavado de dinero o delitos financieros relacionados; deficiencias de información en cuanto a la naturaleza o propósito de cualquier producto de inversión; políticas corporativas o de negocios del asegurado; responsabilidad que pueda surgir de desarrollar actividades u operaciones de crédito; uso ilegítimo de información personal contenida en bases de datos; violación de obligaciones de confidencialidad o de derechos de propiedad intelectual; actos de corrupción y violación de regulaciones en materia de negociación de valores.

Como puede apreciarse, algunas de estas exclusiones se encuentran expresadas de una forma amplia y por lo cual el espectro de actividades que desarrollan las entidades bancarias y financieras y que son materia de protección por este tipo de seguro, resultan reducidas en un grado importante.

\section{El amparo de fraudes por sistemas computarizados}

\subsection{El objeto de la cobertura}

Podría suceder que por accidentes, errores, fraudes, alteración de programas o introducción de virus, se vea afectada la disponibilidad, integridad o confidencialidad de la información y con ello se causen perjuicios al empresario mismo y a su clientela; daños que pueden consistir en perjuicios materiales de distinto orden (dinero, bienes, clientela, oportunidades, etc) y que habría de cubrir el empresario al resultarle imputables los daños en cuestión por quebrantar su deber de custodia, vigilancia y seguridad de sus recursos informáticos.

En esta última área de accidentes, errores, fraudes, alteración de programas o introducción de virus, es donde se ubica la cobertura de pérdidas por utilización de sistemas computarizados y que, ineludiblemente, debe adquirir una entidad financiera para alcanzar una salvaguarda más integral de su patrimonio y que habrá de complementar con una auditoría de sistemas que debe revisarse y actualizarse de manera periódica, como mecanismo para detectar oportunamente nuevos riesgos y que permita evaluarlos de cara a la capacidad financiera de la empresa y de esta manera, se implementen medidas de prevención y reducción de pérdidas y se diseñen planes de contingencia que contribuyan en ese cometido.

El objetivo de la póliza de fraude a través de sistemas computarizados es otorgar amparo respecto de determinados actos dolosos de terceros cometidos contra el asegurado que resulten en transferencia, pago o entrega de dineros o de bienes. 


\subsection{Las tendencias de cobertura en el mercado internacional}

Ante el aumento del número de transacciones electrónicas, este tipo de pólizas cada vez cobra mayor importancia. La cobertura pretende proteger al asegurado en relación con el acceso ilegítimo por parte de terceros que les permita apoderarse de activos a través del acceso o la intrusión en el sistema de cómputo. En el caso de los Estados Unidos de América no se ha presentado una alta litigiosidad bajo este tipo de amparos y por lo tanto, no se han introducido modificaciones en los clausulados que se comercializan.

Finalmente, la tendencia en este tipo de productos es la de restringir la cobertura a la apropiación de dinero y valores derivado del acceso ilegítimo a los sistemas de cómputo y, en el caso colombiano en particular, no se han presentado modificaciones o alteraciones en los productos que se han venido ofreciendo por más de dos décadas.

\section{Las coberturas de cyber risks y de cyber liability}

Como pueden existir circunstancias en las cuales se generen daños a los sistemas de cómputo o daño a las redes de datos sin que ello implique la apropiación de dineros, que generan interrupción o contratiempos en la prestación de servicios de la respectiva entidad, con la consiguiente pérdida de ingresos o el aumento en los costos de operación normales, se han diseñado múltiples productos de seguros orientados a cubrir ese tipo de eventualidades. Son las denominadas cobertura de riesgos cibernéticos, que tienen una estrecha relación con el marco legal de la protección de datos.

Algunas pólizas ofrecen cobertura con respecto a: pérdida o daño de activos digitales; pérdida daño de datos de programas de cómputo que resulten en costos de reposición en que sea precisado a incurrir el asegurado, para su restauración, actualización o reemplazo, en las mismas condiciones que tenían en el momento anterior al daño o pérdida; interrupciones en la operación de la red, lo que incluye interrupción, degradación del servicio o falla en las redes, que resulten en pérdida de ingresos o en aumento en costos de operación o en costos que sea necesario incurrir por el asegurado, para mitigar los daños o para investigar la extensión y el origen de la pérdida; daño a la reputación de la entidad, como consecuencia de una violación a las normas y regulaciones en materia de protección de datos que sea reportada a las entidades regulatorias y que pueda ocasionar pérdida de propiedad intelectual, ingresos, o pérdida de clientes y/o aumento en los costos de operación; pérdida de dinero y de activos digitales, o pérdida monetaria o económica directa asociada con la apropiación de fondos o de dineros a través de la intrusión en los equipos o programas de cómputo, como también como consecuencia de las distintas modalidades de fraude electrónico o por la apropiación de fondos o de dinero de una organización, a través de delitos de carácter informático.

En relación con responsabilidades que pueda incurrir el asegurado, se han diseñado pólizas que incluyen la asistencia o aún la administración del incidente que ocasiona la pérdida o daño a terceros; productos que también comprenden la com- 
pensación económica por el costo que implica solucionar el incidente. En este sentido, también se amparan los costos de defensa y las expensas judiciales en que se incurra en procesos promovidos por fallas en la preservación de la privacidad o seguridad de los sistemas de cómputo, la transmisión de virus o códigos maliciosos, el desconocimiento de protocolos en materia de privacidad respecto de la información almacenada en relación con clientes o empleados; costos incurridos para en la notificación y aviso a la clientela para satisfacer exigencias regulatorias, incluyendo gastos de reputación que puedan estar asociados; responsabilidad por multimedia y consistente en la violación de privacidad, publicación negligente de cualquier contenido de carácter electrónico como también el desconocimiento de derechos de propiedad intelectual; responsabilidad con terceros por daño o detrimento de datos o de información de propiedad de terceros, incluyendo indemnizaciones a clientes por negativa de acceso, falla de los programas de cómputo o errores en datos o fallas en los sistemas de seguridad.

En el caso de algunas coberturas de Internet o de cyber liability, se encuentran diseñadas para las reclamaciones de terceros que configuren una responsabilidad de carácter profesional del asegurado por razón de reclamaciones de derechos de autor o de quebrantamiento de información confidencial. Igualmente se cubren las pérdidas directas del asegurado por razón de infidelidad, crimen por computador y reconstrucción de datos o medios de cómputo.

Todas las coberturas anteriores, como parte del proceso de suscripción y selección de riesgos por parte de las aseguradoras, exigen la realización de test de penetración por parte de firmas especializadas, son los denominados "ethical Hawking" y consisten en una inspección de riesgo, llevada a cabo por un experto en esta clase de eventualidades y no en cuanto a organización bancaria. Se trata de una visión objetiva por lo que constituye una herramienta gerencial y de gestión de riesgos que ofrece soluciones, porque se encuentran basados en experiencias de carácter mundial.

Por último, con respecto a la asegurabilidad este tipo de riesgos, recientemente se han conocido estudios que cuestionan este aspecto, dada la probabilidad de ocurrencia y la potencial severidad que pueden tener en el colapso de infraestructuras de información, por cuanto las estimaciones de pérdidas oscilan entre US \$ 300 billones y 1 trillón ${ }^{65}$.

65 Biener, Christian, Eling, Martín y Hendrik, Jan. "Insurability of cyber risks. An empirical analysis". Working papers on risk management and Insurance, No. 151, January 2015. 


\section{BIBLIOGRAFIA}

\section{Libros}

Altavilla, Enrico "La Culpa", Editorial Temis, 4ạ. Edición, Bogotá, 1999

Armstrong, Edgar y Stevens, Mark "Digest of Bank Insurance", sixth edition, Insurance and Protection Division, American Bankers Association, Washington, 1.977

Barros, Enrique. ("Tratado de responsabilidad extracontractual", Editorial Jurídica de Chile, Santiago, 2009

Benítez, Luis. "Tratado de Seguros", Tomo I, Instituto Editorial Reus, Madrid, 1955

Biener, Christian, Eling, Martín y Hendrik, Jan. "Insurability of cyber risks. An empirical analysis". Working papers on risk management and Insurance, No. 151, January 2015

Cabanellas, Guillermo “Diccionario Enciclopédico de Derecho Usual” Editorial Heliasta S.R.L., $20^{\mathrm{a}}$ edición, Buenos Aires

Connolly, Mark Mark A "Procastinating principals: discovery and notice of claim under fidelity bonds and commercial crime policies", Thirteenth Annual Southern Surety and Fidelity Claims Conference, Charleston, April 25-26, 2002 página 5.

De Ángel, Ricardo. "Una teoría del Derecho". Colección tratados y manuales, Editorial Civitas S.A. Madrid, 1995.

Díaz, María del Pilar "El dolo eventual", Tirant Lo Blanch, Sevilla, 1994

Diez-Picazo, Luis. "Sistema de Derecho Civil “, Tecnos, 6a Edición, 1988

Farina, Juan M. "Contratos Comerciales Modernos" Editorial Astrea, Buenos Aires 1997

García, Miguel. Condiciones generales de los contratos", Editorial Revista de Derecho Privado, Madrid, 1969

Fontanarrosa, Rodolfo. "Introducción al derecho mercantil", Ediciones Doctrina y Ley, Bogotá, 1995

Horkovich, Robert M. "Insurance coverage for employee theft losses: a policyholder primer a commonly litigated issues", University of Memphis Law Review, September 2008

Keely, Michael. Block, Luisa A. "Loan loss coverage under Financial Institutions Bond", American Bar Association, Chicago, 2007

Keely, Michael. Duffy Sean "Handling fidelity bond claims", $2^{\text {nd }}$ Edition, editors American Bar Association, 2005, Chicago, Illinois, USA.

Narváez, José Ignacio. "Introducción al derecho mercantil", Legis Editores, Bogotá, 2002.

Narvaez, Jorge Eduardo "Pérdidas operacionales y amparos de infidelidad bajo las pólizas globales bancarias", Revista Iberolatinoamericana de Seguros, No. 33, enero-junio de 2012, publicación de Aida- Cila y de la Pontificia Universidad Javeriana

Ospina Fernandez, Guillermo "Régimen general de las obligaciones", Editorial Temis Ltda, 4a edición, Bogotá, 1987

Ossa, Efrén. "Teoría General del seguro- El contrato-“, Segunda edición, Editorial Temis Ltda, Bogotá, 1991 
"Proyecto de Código de Comercio", Ministerio de Justicia, Tomo I, julio de 1958

Restrepo, Laura "El amparo de infidelidad de la póliza de seguro global bancario. Análisis desde la perspectiva de las cláusulas abusivas en Colombia", Revista Iberolatinoamericana de Seguros, No. 38, enero-julio de 2013, Pontificia Universidad Javeriana, CILA, FIDES

Rodriguez, Eduardo "Administración del Riesgo", Editorial Alfaomega Colombiana S.A., Bogotá, 2002

\section{Jurisprudencia y Laudos Arbitrales}

Corte Suprema de Justicia. Sala de Casación Civil. Sentencia de 25 de agosto de 2010. M.P. José Leonidas Bustos Martínez. Expediente 32964.

En sentencia de junio 2 de 1958

de Nike Inc vs. Northwestern Indemnity Co. (2000

sentencia C- 909 de 7 de noviembre de 2012, M.P. Nilson Pinilla

sentencia de 4 de febrero de 2010

sentencia C- 909 de 7 de noviembre de 2012, M.P. Nilson Pinilla

laudo de Sociedad Fiduciaria Bermúdez y Valenzuela S.A. en liquidación vs. Aseguradora Colseguros S.A. de 30 de agosto de 2002

laudo de 24 de octubre de 2012 de Proyectar Valores vs. Chubb de Colombia

Laudo de 12 de noviembre de 2014 de Banco de la República contra Seguros Generales Suramericana S.A. y Allianz Seguros S.A.

Laudo arbitral de 9 de diciembre de 2014, Asesorías e Inversiones S.A. vs. AIG Seguros Colombia S.A.

laudo de Andino Capital Markets vs. Interamericana S.A. Cia de Seguros 